IZA DP No. 9798

Cognitive Ability and the Mortality Gradient by

Education: Selection or Mediation?

Govert E. Bijwaard

Andrew M. Jones

March 2016 


\title{
Cognitive Ability and the Mortality Gradient by Education: Selection or Mediation?
}

\author{
Govert E. Bijwaard \\ Netherlands Interdisciplinary Demographic Institute (NIDI) \\ and IZA \\ Andrew M. Jones \\ University of York
}

Discussion Paper No. 9798

March 2016

IZA

P.O. Box 7240
53072 Bonn
Germany

Phone: +49-228-3894-0

Fax: +49-228-3894-180

E-mail: iza@iza.org

\begin{abstract}
Any opinions expressed here are those of the author(s) and not those of IZA. Research published in this series may include views on policy, but the institute itself takes no institutional policy positions. The IZA research network is committed to the IZA Guiding Principles of Research Integrity.

The Institute for the Study of Labor (IZA) in Bonn is a local and virtual international research center and a place of communication between science, politics and business. IZA is an independent nonprofit organization supported by Deutsche Post Foundation. The center is associated with the University of Bonn and offers a stimulating research environment through its international network, workshops and conferences, data service, project support, research visits and doctoral program. IZA engages in (i) original and internationally competitive research in all fields of labor economics, (ii) development of policy concepts, and (iii) dissemination of research results and concepts to the interested public.
\end{abstract}

IZA Discussion Papers often represent preliminary work and are circulated to encourage discussion. Citation of such a paper should account for its provisional character. A revised version may be available directly from the author. 


\section{ABSTRACT \\ Cognitive Ability and the Mortality Gradient by Education: Selection or Mediation?*}

Large differences in mortality rates across those with different levels of education are a wellestablished fact. This association between mortality and education may partly be explained by confounding factors, including cognitive ability. Cognitive ability may also be affected by education so that it becomes a mediating factor in the causal chain. In this paper we estimate the impact of education on mortality using inverse probability weighted (IPW) estimators, using either cognitive ability as a selection variable or as a mediating variable. We develop an IPW estimator to analyse the mediating effect in the context of survival models. Our estimates are based on administrative data, on men born in 1944-1947 who were examined for military service in the Netherlands between 1961-1965, linked to national death records. For these men we distinguish four education levels and we make pairwise comparisons. From the empirical analyses we conclude that the mortality differences observed by education are only attributable to education effects for highly educated individuals. For less educated individuals the observed mortality gain is mainly attributable to differences in cognitive ability.

JEL Classification: C41, I14, I24

Keywords: education, mortality, inverse probability weighting, mediators, mixed proportional hazard

Corresponding author:

Govert E. Bijwaard

Netherlands Interdisciplinary Demographic Institute

(NIDI-KNAW/University of Groningen)

PO Box 11650

2502 AR The Hague

The Netherlands

E-mail: bijwaard@nidi.nl

\footnotetext{
* The authors acknowledge access to linked data resources (DO 1995-2011) by Statistics Netherlands (CBS). We are grateful to seminar participants at Erasmus University Rotterdam, University of York and the Paris School of Economics for helpful comments.
} 


\section{Introduction}

Many studies show large differences in health and mortality across educational groups. This is one of the most compelling and well established associations in social science research and holds across many populations (Grossman 2015). Even in an egalitarian country such as the Netherlands, with a very accessible health care system, the difference in life expectancy between individuals with no formal education beyond primary school and those with a university education is more than five years (Bruggink 2009). Still, the background of these inequalities is not fully understood.

The association between health and education may partly be explained by confounding factors such as cognitive ability and parental background that affect both education choices and health, (McCartney et al. 2013). Lower cognitive ability as measured by standardized IQ tests is related to adult health (Hartog and Oosterbeek 1998; Auld and Sidhu 2005; Conti and Heckman 2010; Kaestner and Callison 2011) and increased mortality (Batty and David 2004; Batty et al. 2007; Calvin et al. 2011). Because educational attainment and cognitive ability are strongly correlated, it is difficult to separate their effects on mortality (Deary and Johnson 2010). For example, both Hartog and Oosterbeek (1998) and Auld and Sidhu (2005) found that the magnitude of the effect of cognitive ability on health was reduced by nearly a half after controlling for schooling.

Studies based on natural experiments in education, including changes in compulsory schooling laws, may to some extent overcome the difficulty of separating true education effects from these confounding factors (Lleras-Muney 2005). Recent analyses of such natural experiments suggest that the causal effect of education on health outcomes may be limited (Mazumder 2008; Jones et al. 2011; Van Kippersluis et al. 2011; Meghir et al. 2013; Basu et al. 2014; Fletcher 2015) or even absent (Albouy and Lequien 2009; Clark and Royer 2013, Jürges et al. 2013). This suggests that confounding factors may well play an important role in shaping the strong association between education and health. However, a major limitation of using changes in compulsory schooling to detect educational effects on health outcomes, and in particular mortality, is that often only a relatively small part of the population is affected by the laws (Mazumder 2008; Fletcher 2015). Another issue with the instrumental variable methods applied in these studies is that they, implicitly, assume that the compulsory schooling reforms only affect long-term health through their effect on education, ignoring any other contemporary policy changes they may accompany these reforms.

Studies based on structural models in which the interdependence between education, health, and cognitive ability is modelled explicitly show that at least half of the health disparities across educational groups is due to selection of healthier, more able individuals into higher education (Conti and Heckman 2010; Conti et al. 2010; Bijwaard et al. 2015). These models reveal that failure to control for cognitive 
ability in health and mortality analyses biases the estimated effect of education. Further, the effect of cognitive ability on health and mortality is of direct interest as higher cognitive ability gives the higher educated their efficiency advantage in terms of health investment (Auld and Sidhu 2005; Bijwaard and van Kippersluis 2015). Although such structural models disentangle the effects of education and cognitive ability on health outcomes, they depend heavily on the assumed structure and distributional assumptions.

A better understanding of the influence of cognitive ability on education and mortality is needed to establish potential direct benefits of improvements in education on mortality. The place of cognitive ability in the causal path from education to mortality has important implications for the analysis. Cognitive ability can be considered a (main) source of education selection and, an endowment that determines the success at school. Then intelligence precedes education in the causal path to health and mortality. However, cognitive ability, at least as measured by standard IQ-tests, is likely to change with the education attained. In that case, cognitive ability is a mediator in the causal path from education to health. Ideally, we would have continuous measurement of the (development) of cognitive ability over the life cycle, to account for both the selection and mediation of cognitive ability in the causal path from education to mortality. However, in our data, we only observe cognitive ability at late adolescence when measured intelligence can be either the result of the attained education or a proxy of early childhood intelligence which influences education choice. In this paper we consider both these two possible roles of cognitive ability in the causal pathway from education to mortality and we investigate how these affect the estimated impact of education on mortality.

When cognitive ability is a mediator we can decompose the effect of education on mortality into an effect running through improvement of cognitive ability and an effect through other pathways. An effect of education through improvement of cognitive ability is likely if education raises cognitive ability that aids disease management and in seeking appropriate treatment where necessary. Other possible pathways from education to mortality if higher education leads to improvement in socioeconomic status later in life, such as labour market signals, non-cognitive skills and peer effects, which influence health and mortality. When cognitive ability is a selection factor we cannot decompose the educational effect on mortality in such a way. But we are able to estimate an education impact corrected for selective education choices that are based on differences in cognitive ability.

Our outcome, the age at death is a duration variable and the mortality hazard rate, the instantaneous probability that an individual dies at a certain age conditional on surviving up to that age, is modelled. Accounting for right-censoring, when the individual is only known to have survived up to the end of the observation window, and left-truncation, when only those individuals are observed who 
were alive at a certain time, are easy to handle in hazard models (Van den Berg 2001). A common way to accommodate the presence of observed characteristics is to specify a proportional hazard model, in which the hazard is the product of the baseline hazard, the age dependence, and a log-linear function of covariates. Neglecting confounding in inherently non-linear models, such as proportional hazard models, leads to biased inference.

Propensity score methods are increasingly used to estimate account for confounding in observational studies, e.g. see Caliendo and Kopeinig (2008) for a survey. The advantage of the propensity score is that it enables us to summarize the many possible confounding covariates as a single score (Rosenbaum and Rubin 1983). With a duration outcome right censoring makes inference of differences in means, as is standard in treatment analysis, unreliable. Propensity score methods for hazard models have been introduced for duration data that account for censoring, truncation and dynamic selection issues (Cole and Hernán 2004; Austin 2014). We apply inverse probability weighting (IPW) methods using the propensity score (Hirano et al. 2003), which belongs to the larger class of marginal structural models that account for time-varying confounders when estimating the effect of time-varying covariates (Robins et al. 2000).

Under the assumption that cognitive ability is a mediator of the education effect on mortality we also extend these methods to mediation analysis for (mixed) proportional hazard (MPH) models. The main methodological contribution of this paper is that we disentangle the total effect of a treatment on a duration into an effect that runs through the mediator and an effect through other pathways. We derive and implement an IPW estimator for such decomposition of the total effects in MPH models. The estimator identifies causal mechanisms given that a sequential unconfoundedness condition holds.

In our empirical analyses we use administrative data on Dutch men who were examined for military service in the Netherlands between 1961-1965 after completing their secondary schooling. We followed 45,037 men selected from the national birth cohorts 1944-1947. These examinations are based on yearly listings of all Dutch male citizens aged 18 years in the national population registers. The sampled examination records were linked by Statistics Netherlands to recent national death records (up to 2012). The records include a standardized recording of demographic and socioeconomic characteristics such as education, father's occupation, religion, family size, and birth order, along with a standardized psychometric test battery. The educational level was classified in four categories: primary school, lower vocational education, lower secondary education, and intermediate vocational education, general secondary education, higher non-university and university education.

The empirical results show that improving education has hardly any impact on the mortality rate when accounting for cognitive ability. Only for the lowest education group we find a significant 
mortality reduction of $11 \%$ when these men would have improved their education. Using the mediation method we only find a significant effect of education on mortality running through cognitive ability, for this group that amounts to a $15 \%$ reduction in the mortality rate. For the highest education group we find a significant effect of education through other pathways on mortality of $12 \%$.

\section{Data}

Data from a large sample from the nationwide Dutch Military Service Conscription Register for the years 1961-1965 and male birth cohorts 1944-1947 are analysed. All men, except those living in psychiatric institutions or in nursing institutes for the blind or for the deaf-mute, were called to a military service induction exam. The majority attended the conscription examination at age 18 . We have information from the military examinations for 45,037 men. The data were described elsewhere, (Ekamper et al. 2014), here we provide the main characteristics. These data were linked to the Dutch death register through to the end of 2012 using unique personal identification numbers. Follow-up status was incomplete (due to emigration and other right-censoring events) for 1,316 (2.9\%) and entirely unknown for 2,625 (5.8\%) men. The latter were removed from the data. These data allow us to follow a large group of men from age 18 until age 70 or until death. At the military examination a standardized recording of demographic and socioeconomic characteristics such as education, father's occupation, religion, family size, region of birth, and birth order is recorded. We exploit the information on education attained at age 18 and the age at death to investigate the mortality difference while accounting for other factors that both influence educational level and mortality.

The educational level was classified in four categories ${ }^{1}$, (Doornbos and Kromhout 1990): primary school (age 6-12 years); lower vocational education (two years post primary school); lower secondary education (four years post primary school); and intermediate vocational education, general secondary education, higher non-university and university education (at least six years post primary school). For this study, we excluded partly institutionalized conscripts who had attended special schools for the illiterate, handicapped, deaf-mute, or mentally retarded, and conscripts who had not completed schooling 12 years of schooling. After exclusion of these 2,614 conscripts, 39,798 men remain for analysis.

A standardized psychometric test battery is included: comprising Raven Progressive Matrices,

\footnotetext{
${ }^{1}$ Education in the Netherlands is characterized by education years and by school level. There are two parallel streams in the educational system: general academic and vocational. Streaming choices are made at the end of primary school. Students in the vocational stream cannot directly enter university. Students with more than twelve years of education will nearly always be in the academic stream (Schröder and Ganzeboom 2014; Vrooman and Dronkers 1986).
} 
a nonverbal untimed test that requires inductive reasoning about perceptual patterns, the Bennett Mechanical Comprehension test, and tests for Clerical Aptitude, Language Comprehension, Arithmetic and a Global comprehensive score, that combines all five tests. All tests were administered to over $95 \%$ of the population who were examined at induction. Scores for all tests were grouped in six levels from 1 (highest) to 6 (lowest). The test scores are highly correlated with Pearson's $r$ values in the range of .63 to .76. Here, we only focus on the scores of the comprehensive test.

Selected demographic and socioeconomic characteristics at the time of military examinations by education level are given in Table 1. First born conscripts tend to have higher education. Father's occupation was classified into five categories: professional and managerial workers; clerical, self-employed and skilled workers; farmers; semi-skilled workers including operators, process workers and shop assistants; and labourers and miners. Fathers with unknown occupations were classified separately. Education level is also strongly related to father's occupation; men with the highest education tend to have fathers in professional or managerial occupations. The place of birth was categorized in four urbanization levels based on agrarian and total population size. This distinguishes rural communities (rural communities with $20 \%$ or more farming population), urbanized rural communities (rural communities with less than $20 \%$ farming population), towns (townships and cities with less than 100,000 inhabitants), and cities with populations of 100,000 or more. Men from rural areas are lower educated on average. The combined cognition measure is the Global comprehensive score. Not surprisingly, men with the highest education tend to do best on the comprehensive IQ test. Our principal measure of health is mortality with ages of death ranging from 18 up to 70 . The lowest education group has a $70 \%$ higher mortality.

The Kaplan-Meier survival curves for the four education categories are shown in Figure 1 and reflect these mortality differences. Survival increases with the education level and the differences between the education levels increase with age. The curves differ significantly $\left(\chi^{2}=147.61\right.$ for a log-rank test with 3 degrees of freedom). In subgroup analyses, survival differences comparing adjacent education levels are also statistically significant $\left(\chi^{2}=45.77,5.79,28.72\right)$. This mortality difference by education is not necessarily due to education per se. It could be that the higher cognitive ability of higher educated people causes the difference. For example, understanding a doctor's advice and adhering to complex treatments may be driven by cognitive ability rather than education. From Table 1 we have seen already that education and IQ are highly correlated. Figure 2 shows that survival also increases with IQ and the differences are statistically significant $\left(\chi^{2}=239.54\right.$ for a log-rank test with 5 degrees of freedom). For all, except the two lowest, adjacent IQ levels the differences in the Kaplan-Meier survival curves are significant. Within each education level the Kaplan-Meier curves also differ significantly by 
Table 1: Sample distribution by education level

\begin{tabular}{l|rrrr|r}
\hline \hline & $\begin{array}{r}\text { Primary } \\
\text { education }\end{array}$ & $\begin{array}{r}\text { Lower } \\
\text { vocational }\end{array}$ & $\begin{array}{r}\text { Lower } \\
\text { secondary }\end{array}$ & $\begin{array}{r}\text { Higher } \\
\text { education }\end{array}$ & $\begin{array}{r}\text { All } \\
\text { levels }\end{array}$ \\
\hline Birth order: & & & & & \\
1 & 27.8 & 32.1 & 39.3 & 42.6 & 35.5 \\
2 & 27.1 & 30.3 & 30.7 & 29.9 & 29.9 \\
3 & 18.7 & 18.4 & 16.3 & 15.4 & 17.3 \\
4 & 11.3 & 9.2 & 6.9 & 7.0 & 8.4 \\
$\geq 5$ & 14.9 & 10.0 & 6.7 & 5.1 & 8.8 \\
Place of birth: & & & & & \\
City & 76.0 & 74.4 & 82.1 & 83.3 & 78.6 \\
Town & 8.8 & 7.6 & 6.7 & 7.2 & 7.4 \\
Urbanized Rural & 2.8 & 2.7 & 2.0 & 1.7 & 2.3 \\
Rural & 12.5 & 15.3 & 9.2 & 7.8 & 11.7 \\
\hline Father's occupation: & & & & & \\
Professional & 8.7 & 10.2 & 17.2 & 39.0 & 17.0 \\
White collar & 19.7 & 29.7 & 42.8 & 42.9 & 34.8 \\
Farm owner & 3.0 & 5.7 & 2.2 & 1.7 & 3.5 \\
Skilled & 38.4 & 33.3 & 23.1 & 9.2 & 26.7 \\
Unskilled & 22.5 & 14.9 & 9.4 & 3.4 & 12.3 \\
Unknown & 7.7 & 6.2 & 5.3 & 3.9 & 5.7 \\
\hline Global comprehensive IQ score: & & & & & \\
1 (highest) & 0.1 & 6.3 & 19.8 & 54.6 & 17.6 \\
2 & 3.8 & 27.5 & 47.9 & 37.7 & 32.5 \\
3 & 13.7 & 30.3 & 20.9 & 4.0 & 20.6 \\
4 & 28.3 & 22.7 & 7.2 & 0.6 & 14.9 \\
5 & 39.5 & 10.6 & 1.7 & 0.1 & 10.1 \\
6 (lowest) & 11.5 & 0.8 & 0.1 & 0.02 & 2.0 \\
\hline Total \# of deaths & 1,213 & 2,522 & 2,109 & 827 & 5,350 \\
\% died & 21.2 & 17.3 & 16.1 & 12.9 & 16.8 \\
\hline Sample size & 5,712 & 14,572 & 13,124 & 6,390 & 39,798 \\
\hline \hline
\end{tabular}

IQ-level (not shown here).

Next we investigate the relationship between IQ and educational attainment. The IQ scores are measured on a six-point ordinal scale. Comparing individuals on the extremes of the education level is not helpful as these individuals differ too much in many respects. We focus on adjacent education levels only and estimate separate ordered probit models for the IQ-score in relation to the highest education level in each pair and other observed individual characteristics. The results of ordered probit analyses reveal a strong association between education and IQ. ${ }^{2}$

\footnotetext{
${ }^{2}$ See Table B.1 in Appendix B.
} 
Figure 1: Kaplan-Meier survival curves, by education level

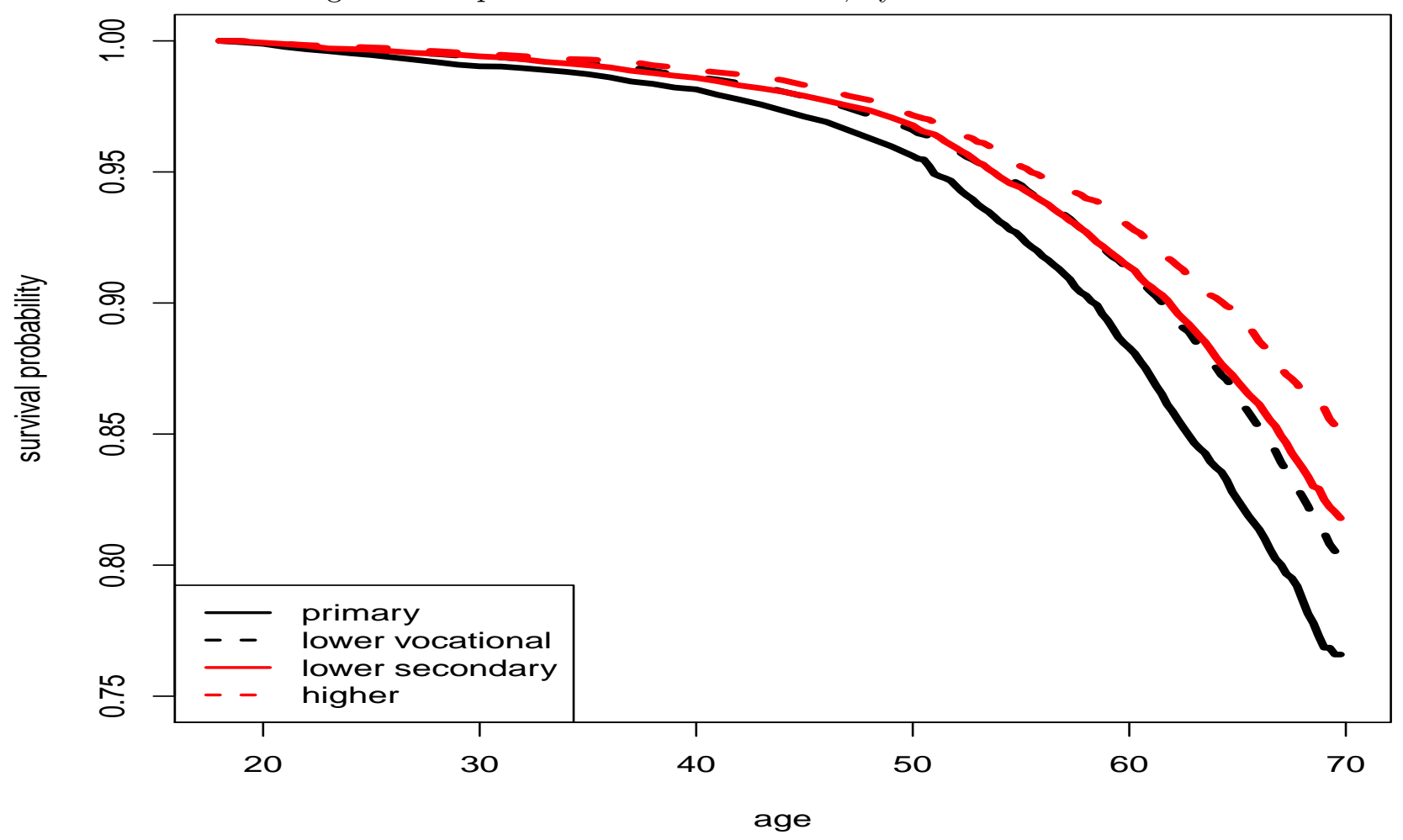

Figure 2: Kaplan-Meier survival curves, by IQ level (overall level)

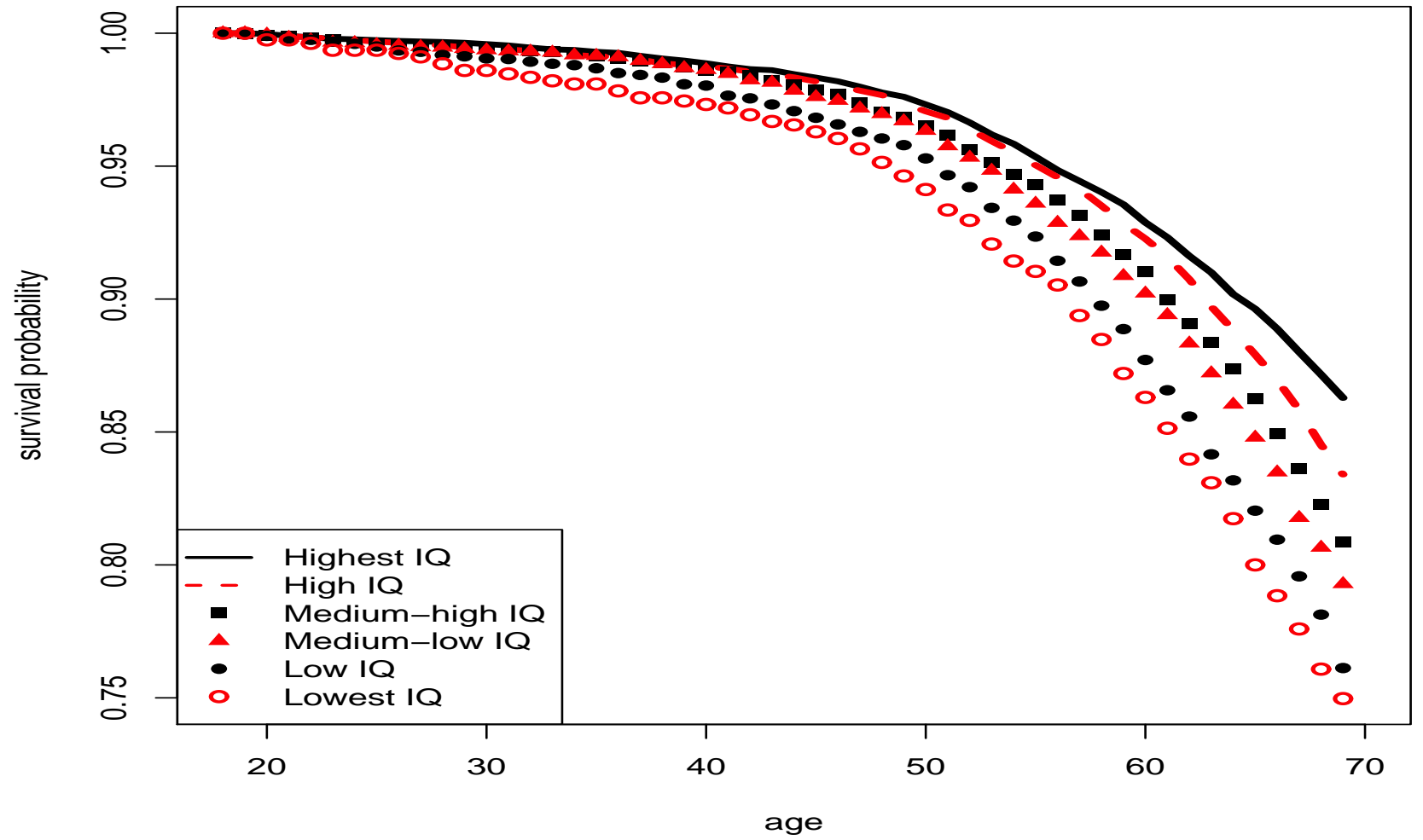




\section{Defining the effect of education on the mortality hazard rate}

We seek to find the impact of education level on the mortality risk for the men in our sample of conscripts. However, mortality may be influenced by factors that also determine the education choice. This may render education a selective choice and makes it endogenous to mortality later in life. We follow a propensity score method to account for selection on observed characteristics and estimate the effect of education on the mortality rate. From the descriptive analyses in the previous section is it obvious that cognitive ability, measured by an IQ-test, influences both the education attained and the mortality later in life. However, cognitive ability as measured at age 18, the age at military examination, is also influenced by the education taken up to that age (Ceci 1991; Hansen et al. 2004; Carlsson et al. 2015). Figure 3 provides a graphical illustration of the relationship between cognitive ability, education and mortality later in life using a directed acyclic graph, where each arrow represents a causal path (Pearl 2000; Pearl 2012). It states that early childhood characteristics $X$, such as parental background and family size, influence the education choice $D$, the early childhood cognitive ability, $Q_{0}$, and the cognitive ability at age $18, Q_{18}$. The latter is also influenced by early life cognitive ability and the education followed up to age 18. In our data we do not observe early childhood cognitive ability $\left(Q_{0}\right)$.

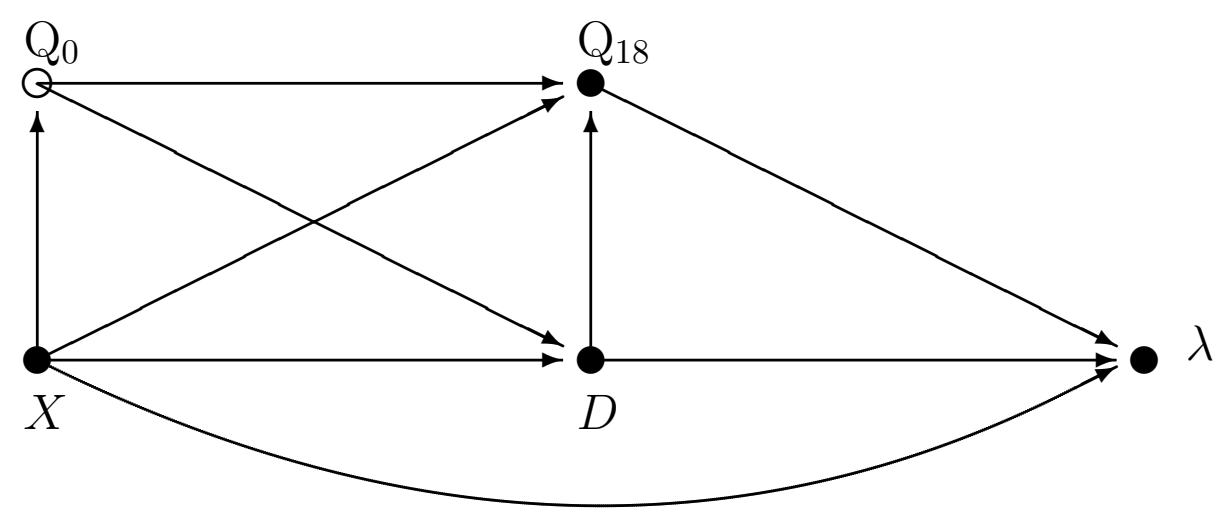

Figure 3: Directed acyclic graph of possible relation between cognitive ability, Q, education, $D$, and mortality $\lambda$ conditional on $X$

We will investigate how different assumptions of the place of cognitive ability at age 18 in the causal path from education to mortality affects the estimated impact of education on mortality. In Section 4 we assume that cognitive ability at age 18 is a proxy for the cognitive ability early in life and is one of the factors that influence both the education choice and the mortality. In Section 5 we assume 
that education raises cognitive ability and a model in which cognitive ability at age 18 mediates the impact of education on mortality is introduced. This allows us to decompose the effect of education on mortality into an effect running through improvement of cognitive ability and an effect through other pathways. Before we discuss these models we define how we measure the impact of education on mortality.

We define the treatment effect, of moving up one education level, in terms of a proportional change in the (mortality) hazard rate. First, we discuss the assumptions, common in the potential outcomes literature that uses propensity score methods, to identify the impact of education on the mortality risk. In Section 5 we extend this to this to decompose the effect of education on the mortality rate into an effect running through improvement in cognitive ability and an effect running through other pathways. The main difference with standard propensity score methods is that we use potential hazard rates, the hazard rate that would be observed if the individual was untreated, $\lambda(t \mid 0)$, or treated $\lambda(t \mid 1)$. Let $D_{i}=1$ be the treatment, moving up one education level. We observe pre-treatment (educational level) covariates $X$ that influence the education choice.

Assumption 1. Unconfoundedness: $\lambda(t \mid d) \perp D \mid X$ for $d=0,1$

where $\perp$ denotes independence. The unconfoundedness assumption (Rubin 1974, Rosenbaum and Rubin 1983) asserts that, conditional on covariates $X$, treatment assignment (education level) is independent of the potential outcomes. This assumption requires that all variables that affect both the mortality and the education choice are observed. Note that this does not imply that we assume all relevant covariates are observed. Any missing factor is allowed to influence either the outcome or the education choice, not both. Although this is not testable and clearly a strong assumption, it may be a reasonable approximation. Any alternative, that does not rely on unconfoundedness while allowing for consistent estimation of the average treatment effects, will have to make alternative untestable assumptions. We check the robustness of our estimates to this unconfoundedness assumption by assessing to what extent the estimates are robust to violations of this assumption induced by an additional binary variable.

Assumption 2. Overlap: $0<\operatorname{Pr}(D=1 \mid X)<1$.

The overlap, or common support assumption requires that the propensity score, the conditional probability to choose a higher education given covariates $X$, is bounded away from zero and one. This 
assumption is in principle testable. If there are values of the covariates for which the probability of choosing a higher education level is zero or one, we cannot compare the 'treated' and 'control' individuals at these values. In that case we have to limit comparisons to sets of values where there is sufficient mass in the propensity score among both treated and controls. In our data we distinguish four (ordered) education levels in line with the contemporary Dutch education system (see Section 2). By comparing only adjacent education levels we remove the overlap problems.

We are interested in estimating the average treatment on the treated (ATT) and the average treatment on the untreated (ATU). The ATT provides the average effect of education on mortality to those who obtained a higher education level, while the ATU provides the average effect of education for the lower educated had they obtained a higher education level. We can weaken the two assumptions in both instances. When interested in the ATT:

Assumption 1'. Unconfoundedness for controls: $\lambda(t \mid 0) \perp D \mid X$

Assumption $2^{\prime}$. ATT Overlap: $\operatorname{Pr}(D=1 \mid X)<1$.

While, if we are interested in estimating the ATU, the two assumptions can be weakened to:

Assumption 1". Unconfoundedness for treated: $\lambda(t \mid 1) \perp D \mid X$

Assumption 2". ATU Overlap: $\operatorname{Pr}(D=1 \mid X)>0$.

Rosenbaum and Rubin (1983) show that if the potential outcomes are independent of treatment conditional on covariates $X$, they are also independent of treatment conditional on the propensity score, $p(x)=\operatorname{Pr}(D=1 \mid X=x)$. Hence if unconfoundedness holds, all biases due to observable covariates can be removed by conditioning on the propensity score (Imbens 2004). The average effects can be estimated by matching or weighting on the propensity score. Here we use weighting on the propensity score. Inverse probability weighting based on the propensity score creates a pseudopopulation in which the education choice is independent of the measured confounders. The pseudopopulation is the result of assigning to each individual a weight that is proportional to the inverse of their propensity score. Inverse probability weighting (IPW) estimation is usually based on normalized weights that add to unity. Suppose we have a sample of $n$ individuals, then based on an estimate of the propensity score, $\hat{p}(x)$, estimators of ATE, ATT and ATU are all of the form $\sum_{i}\left[W_{i} \cdot D_{i} \cdot Y_{i}-W_{i}\right.$. 
$\left.\left(1-D_{i}\right) \cdot Y_{i}\right]$ with weights normalised to one:

$$
\begin{aligned}
W_{i, \mathrm{ATE}} & =\left[\frac{D_{i}}{\hat{p}\left(X_{i}\right)} / \sum_{j=1}^{n} \frac{D_{j}}{\hat{p}\left(X_{j}\right)}\right]+\left[\frac{\left(1-D_{i}\right)}{1-\hat{p}\left(X_{i}\right)} / \sum_{j=1}^{n} \frac{1-D_{j}}{1-\hat{p}\left(X_{j}\right)}\right] \\
W_{i, \mathrm{ATT}} & =D_{i}+\left[\frac{\left(1-D_{i}\right) \cdot \hat{p}\left(X_{i}\right)}{1-\hat{p}\left(X_{i}\right)} / \sum_{j=1}^{n} \frac{\left(1-D_{j}\right) \cdot \hat{p}\left(X_{j}\right)}{1-\hat{p}\left(X_{j}\right)}\right] \\
W_{i, \mathrm{ATU}} & =\left[\frac{D_{i} \cdot\left(1-\hat{p}\left(X_{i}\right)\right)}{\hat{p}\left(X_{i}\right)} / \sum_{j=1}^{n} \frac{D_{j} \cdot\left(1-\hat{p}\left(X_{j}\right)\right)}{\hat{p}\left(X_{j}\right)}\right]+\left(1-D_{i}\right)
\end{aligned}
$$

In survival analysis it is standard to compare the (non-parametric) Kaplan-Meier curves for the treated and the controls. The unadjusted survival curves may be misleading due to confounding. Cole and Hernán (2004) describe a method to estimate the IPW adjusted survival curves. Biostatisticians usually focus on Cox regression models and Cole and Hernán (2004) describe how Cox proportional hazard models can be weighted by the inverse propensity score to estimate causal effects of treatments. This method is related to the $g$-computation algorithm of Robins and Rotnitzky (1992) and Robins et al. (2000). The standard Cox model, without additional covariates, assumes that the hazard is:

$$
\lambda(t \mid D)=\lambda_{0}(t) \exp (\gamma D)
$$

where $\lambda_{0}(t)$, the duration or age dependence, is left unspecified. The partial likelihood method (see e.g. Kalbfleisch and Prentice (2002)) provides an estimate of $\gamma$. The IPW Cox model is based on the weighted Cox partial likelihood score for $\gamma$ :

$$
S(\gamma)=\sum_{i=1}^{N} \delta_{i} W_{i}\left[D_{i}-\frac{\sum_{j} Y_{j}\left(t_{i}\right) W_{j} D_{j} \exp \left(\gamma D_{j}\right)}{\sum_{j} Y_{j}\left(t_{i}\right) W_{j} \exp \left(\gamma D_{j}\right)}\right]
$$

where $Y_{j}\left(t_{i}\right)=I\left(t_{j} \geq t_{i}\right)$, the indicator that individual $j$ is in the risk set at time $t_{i}$, the 'standard' counting process at-risk indicator (see Appendix A and the references therein) and $\delta$ indicates whether the duration for individual $i$ is censored $\delta_{i}=0$ or not. The IPW estimator of $\gamma$ solves $S(\gamma)=0$ and is consistent if the model for the propensity score is correctly specified and the Cox model holds (Robins 1999). ${ }^{3}$ Note that in a proportional hazard context it is natural to define the treatment effect proportionally, i.e. $e^{\gamma}=\lambda\left(t \mid D=D^{1}\right) / \lambda\left(t \mid D=D^{0}\right)$ instead of as a difference.

In economics the interest is often also in the duration dependence. The Gompertz hazard, which assumes that the hazard increases exponentially with age, $\lambda_{0}(t)=e^{\alpha_{0}+\alpha_{1} t}$, is known to provide accurate mortality hazards (Gavrilov and Gavrilova 1991). However, it is hardly ever possible to include all relevant factors, either because the researcher does not know all the relevant factors or because it is not possible to measure then. Ignoring such unobserved heterogeneity or frailty may

\footnotetext{
${ }^{3}$ See Appendix A for an alternative proof.
} 
have a huge impact on inference in proportional hazard models, see e.g. Van den Berg (2001). A common solution is to use a Mixed Proportional Hazard (MPH) model, in which it is assumed that all unmeasured factors and measurement error can be captured in a multiplicative random term $V$. The hazard rate becomes ${ }^{4}$

$$
\lambda(t \mid D, V)=V \lambda_{0}(t) \exp (\gamma D)
$$

The (random) frailty $V>0$ is time-invariant and independent of the observed characteristics $X$ and treatment $D$. Note that independence of $V$ and $D$ is crucial, otherwise Assumption 1 would be violated. So, we assume that some factors influencing the mortality rate are not observed and that these factors do not influence the education choice. In the empirical application it is assumed that $V$ has a gamma-distribution; a common assumption used in the empirical literature.

To adjust for confounding we estimate a standard MPH model, that does not include the measured confounders as covariates, using the re-weighted pseudo-population. Fitting a (mixed) proportional hazard model in the pseudo-population is equivalent to fitting a weighted MPH model in the original sample. The parameters of such weighted MPH models can be used to estimate the causal effects of education on mortality in the original sample. The IPW estimator in the (M)PH model is equivalent to solving the weighted derivatives of the log-likelihood:

$$
U(\theta)=\sum_{i=1}^{N} W_{i}\left[\delta_{i} \frac{\partial \log \lambda\left(t_{i} \mid \cdot\right)}{\partial \theta}-\frac{\partial \Lambda\left(t_{i} \mid \cdot\right)}{\partial \theta}\right]
$$

where $\theta$ is the vector of parameters of the hazard in (6) and $\Lambda(t \mid \cdot)=\int_{0}^{t} \lambda(s \mid \cdot) d s$, the integrated hazard. $^{5}$

\section{Model with cognitive ability included in the selection factors}

First, we ignore that cognitive ability may influence both the education choice and the mortality later in life. The framework presented so far considers only two possible states for each individual, either treated or untreated. This is too restrictive for our application. One option would be to estimate an ordered probit propensity score for our four ordered educational choices, see Imai and van Dyk (2004) and Feng et al. (2012). However, men in the lowest and highest education group differ too much in their observed covariates and IQ (see Section 2), which causes severe overlap problems (contradicting Assumption 2). We therefore define the effect of education through pairwise comparisons (Lechner 2002) of adjacent education levels: primary to lower vocational, lower vocational to lower secondary and lower secondary to higher education. For each comparison we estimate a separate propensity score

\footnotetext{
${ }^{4} \mathrm{~A}$ Cox MPH model is also possible, but harder to estimate. We focus on a Gompertz MPH model.

${ }^{5}$ In Appendix A we provide a counting process interpretation and prove consistency.
} 
of attaining the highest education level, (see Table B.2 in Appendix B ). We include variables that influence both the propensity score and mortality: father's occupation, family size, regional dummies, famine birth cohorts and health indicators. For all three education comparisons the occupation of the father plays a crucial role in the propensity score. Religion only influences the education choice of the lowest educated. Health indicators at the military examination are also related to the education attained.

We estimate an unweighted Cox model, a Gompertz model and a Gompertz model with Gamma distributed unobserved heterogeneity (Gamma-Gompertz model). Table 2 presents the estimated effect on the mortality hazard of moving up one educational level for the Cox and the Gamma-Gompertz model (the results for the PH Gompertz model were very close to the results of the PH Cox model and are therefore not shown here). We conclude from these analyses that for the lower educated, with only primary education, and for the lower secondary educated obtaining more education reduces their mortality rate (around 20\%). Moving from lower vocational education to lower secondary education does not change the mortality rate (except when using the treatment effect on the treated). Not adjusting for selective education choice overestimates the impact of education. The treatment effect on the untreated is larger than the treatment effect on the treated. Thus inducing the lower educated to get more education would lead to a higher gain. Accounting for unobserved heterogeneity increases the impact of education for the men moving from lower secondary to higher education, see second panel of Table 2.

Table 2: Impact of education levels on the mortality rate

\begin{tabular}{r|c|ccc}
\hline \hline & & \multicolumn{3}{|c}{ IPW estimate } \\
& Unadjusted & ATE & ATT & ATU \\
\hline Cox & & & & \\
Primary to & $-0.236^{* *}$ & $-0.185^{* *}$ & $-0.160^{* *}$ & $-0.218^{* *}$ \\
lower vocational & $(0.035)$ & $(0.039)$ & $(0.040)$ & $(0.038)$ \\
Lower vocational to & $-0.071^{+}$ & -0.052 & $-0.070^{+}$ & -0.046 \\
lower secondary & $(0.030)$ & $(0.031)$ & $(0.032)$ & $(0.032)$ \\
Lower secondary to & $-0.220^{* *}$ & $-0.190^{* *}$ & $-0.169^{* *}$ & $-0.197^{* *}$ \\
higher & $(0.041)$ & $(0.046)$ & $(0.044)$ & $(0.049)$ \\
\hline Gamma-Gompertz & & & & \\
Primary to & $-0.245^{* *}$ & $-0.185^{* *}$ & $-0.160^{* *}$ & $-0.230^{* *}$ \\
lower vocational & $(0.042)$ & $(0.039)$ & $(0.040)$ & $(0.045)$ \\
Lower vocational to & $-0.071^{+}$ & -0.052 & $-0.070^{+}$ & -0.046 \\
lower secondary & $(0.030)$ & $(0.031)$ & $(0.032)$ & $(0.032)$ \\
Lower secondary to & $-0.231^{* *}$ & $-0.216^{* *}$ & $-0.190^{* *}$ & $-0.221^{* *}$ \\
higher & $(0.045)$ & $(0.053)$ & $(0.051)$ & $(0.055)$ \\
\hline \hline
\end{tabular}

${ }^{+} p<0.05$ and ${ }^{* *} p<0.01$

For an IPW method to hold we need to check if the propensity score is able to balance the 
distribution of all included variables in both the control and treated group. One suitable way to check whether there are still differences is by calculating the standardized bias, or normalised difference in means:

$$
100 \cdot \frac{\bar{x}_{1}-\bar{x}_{0}}{\sqrt{0.5\left(\operatorname{Var}\left(x_{1}\right)+\operatorname{Var}\left(x_{0}\right)\right)}}
$$

Table 3 shows the percentage bias measure before and after adjusting the data for the IQ-test categories (Table B.3 in Appendix B contains the percentage bias for the other covariates). They reveal substantial imbalances between those who attained adjacent education levels. These imbalances disappear for the non-IQ characteristics when we use the inverse propensity weights. However, the outcomes of the IQ-test are not balanced after weighting with propensity scores that ignore IQ scores. This indicates we should include the IQ-test in the propensity score.

Table 3: Standardized bias before and after matching, pairwise comparisons

\begin{tabular}{l|rr|rr|rr}
\hline \hline & \multicolumn{2}{|c|}{$\begin{array}{l}\text { Primary to } \\
\text { lower vocational }\end{array}$} & \multicolumn{2}{|c|}{$\begin{array}{c}\text { Lower vocational to } \\
\text { lower secondary }\end{array}$} & \multicolumn{2}{c}{ Lower secondary to } \\
higher \\
& Before & After & Before & After & Before & After \\
\hline Comprehensive IQ: & & & & & & \\
1 (highest) & -35.0 & 34.8 & 40.8 & 34.3 & 77.1 & 73.3 \\
2 & 69.3 & 65.4 & 43.0 & 38.6 & -20.9 & -19.4 \\
3 & 41.0 & 36.1 & -21.7 & -18.8 & -20.9 & -51.3 \\
4 & -12.9 & -16.6 & -44.4 & -40.1 & -34.5 & -33.6 \\
5 & -70.8 & -67.6 & -37.9 & -34.3 & -16.6 & -15.2 \\
6 (lowest) & -45.5 & -37.0 & -10.6 & -9.2 & -3.5 & -2.6 \\
\hline \# obs & \multicolumn{3}{|c|}{20,272} & \multicolumn{2}{c|}{27,687} & \multicolumn{2}{c}{19,497} \\
\hline \hline
\end{tabular}

Next, we assume that cognitive ability at age 18 is a proxy for the cognitive ability early in life and is one of the factors that influence both the education choice and the mortality. The selection model we assume is illustrated by the DAG in Figure 4

We re-estimate the propensity scores, now including the outcome of the IQ-test. The results confirm a large association of IQ with educational level. ${ }^{6}$ Based on these propensity scores we calculate, for each pairwise education comparison, the standardized bias, using (8). Including IQ in the propensity score removes most of the imbalance in the values of the IQ-test between adjacent education levels (see Table B.5 in Appendix B).

Based on these new propensity scores we re-estimate the MPH models of the impact of education on the mortality rate. Columns 3 to 5 in Table 4 present the estimated effects on the mortality hazard of moving up one educational level for the Cox and the Gamma-Gompertz model. Accounting for selection on IQ removes most of the significant impact of education on mortality. Now, only men who

\footnotetext{
${ }^{6}$ See Table B.4 in Appendix B for the full parameter estimates of the probit results.
} 


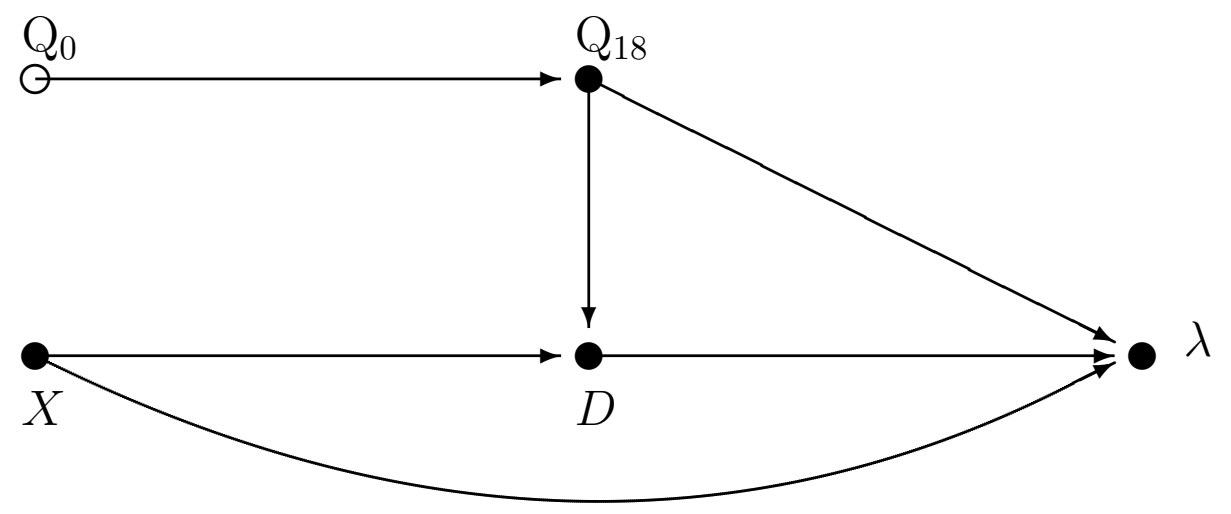

Figure 4: Directed acyclic graph of selection on IQ

have no more than a primary education would gain from moving up the education ladder, with a $12 \%$ reduction in mortality.

Table 4: IPW-total effect including IQ-score in propensity score

\begin{tabular}{r|c|ccc}
\hline \hline & \multicolumn{3}{|c}{ Cox } \\
& $\begin{array}{c}\text { Unadjusted } \\
\text { Robust }\end{array}$ & ATE & IPW & \\
& $-0.093^{+}$ & -0.026 & 0.024 & $-0.108^{+}$ \\
\hline Primary to & $(0.042)$ & $(0.056)$ & $(0.070)$ & $(0.050)$ \\
lower vocational & 0.029 & 0.029 & 0.016 & 0.029 \\
Lower vocational to & $(0.034)$ & $(0.035)$ & $(0.037)$ & $(0.039)$ \\
lower secondary & $-0.104^{+}$ & -0.091 & -0.090 & -0.088 \\
Lower secondary to & $(0.047)$ & $(0.061)$ & $(0.050)$ & $(0.076)$ \\
higher & $(0.050)$ & Gamma-Gompertz \\
Primary to & $-0.101^{+}$ & -0.026 & 0.025 & $-0.115^{+}$ \\
lower vocational & $(0.056)$ & $(0.056)$ & $(0.070)$ & $(0.055)$ \\
Lower vocational to & 0.033 & 0.029 & 0.016 & 0.032 \\
lower secondary & $(0.036)$ & $(0.035)$ & $(0.037)$ & $(0.042)$ \\
Lower secondary to & $-0.116^{+}$ & -0.109 & -0.104 & -0.104 \\
higher & $(0.053)$ & $(0.073)$ & $(0.060)$ & $(0.088)$ \\
\hline \hline
\end{tabular}

${ }^{+} p<0.05$ and ${ }^{* *} p<0.01$ 


\subsection{Sensitivity analyses}

Throughout we have assumed that the propensity scores are estimated consistently. Misspecification of the propensity score will generally produce bias. An approach to improve the robustness of the proposed methodology can be obtained using a doubly robust estimator which also includes a regression adjustment. Rotnitzky and Robins (1995) point out that if either the regression adjustment or the propensity score is correctly specified the resulting estimator will be consistent. Thus we also estimate doubly robust estimators of the models, including the observed characteristics and the IQ-test both in the propensity score and in the hazard regression. Including regression covariates hardly changes the IPW estimates (not shown here). Not surprisingly, including the covariates does change the "unadjusted" results, see column 2 in Table 4.

The critical assumption in propensity score weighting is that of no selection on unobservables. To test the sensitivity of matching estimators to the unconfoundedness assumption we build on the sensitivity analyses of Nannicini (2007) and Ichino et al. (2008). We extend this to the (mixed) proportional hazard. ${ }^{7}$ The Ichino et al. (2008) sensitivity analysis assumes that the possible unobserved confounding factors can be summarised in a binary variable, $U$, and that the unconfoundedness assumption holds conditional on $X$ and $U$, i.e. $\lambda(t \mid 0) \perp D \mid X, U$. Given the values of the probabilities that characterize the distribution of $U$ we can simulate a value of the unobserved confounding factor for each individual and re-estimate the IPW-Cox. The probabilities of the distribution of $U$ depend on the value of the treatment and the outcome. The Ichino et al. (2008) sensitivity analysis assumes that the potential outcomes are binary, but Nannicini (2007) shows how to extend this to continuous outcomes by imposing a binary transformation. In survival analysis we have a natural binary transformation, the censoring indicator $\delta_{i}=1$ if individual $i$ is still alive at the end of the observation period. Then, the distribution of the unobserved binary confounding factor $U$ can be characterised by specifying the probabilities in each of the four groups.

$$
p_{i j}=\operatorname{Pr}(U=1 \mid D=i, \delta=j, X)=\operatorname{Pr}(U=1 \mid D=i, \delta=j)
$$

for $i, j=0,1$.

A measure of how the different configurations of $p_{i j}$, chosen to simulate $U$, translate into associations of $U$ with the outcome and the treatment is $\omega$, the coefficient of $U$ in a Cox model for the control group ( $D=0)$ using $U$ and $X$ as covariates. Ichino et al. (2008) call this (exponentiated) coefficient the 'outcome effect'. A measure of the effect of $U$ on the relative probability to be assigned to the

\footnotetext{
${ }^{7}$ Here we only focus on the effect in the Cox model. The methods can easily be extended to the Gompertz model or the Gompertz model with unobserved heterogeneity.
} 
treatment is $\xi$, with $\xi$ the coefficient of $U$ in a logit model on the treatment assignment $(D=1)$ using $U$ and $X$ as covariates. Ichino et al. (2008) call this (exponentiated) coefficient the 'selection effect'.

Next we re-estimate the IPW-Cox treatment effects including $U$ in the propensity score. The probability values of the distribution for $U$ are chosen so that they mimic the distribution for each included binary variable. For example, consider the probability that an individual in the lowest education group (primary and lower vocational education) is a catholic. Then, $p_{00}$ is this probability for those with primary education who died before the end of the observation period, $p_{01}$ is the probability for those with primary education who survived till the end, $p_{10}$ is the probability for those with lower vocational education who died before the end, and $p_{11}$ is the probability for those with lower vocational education who survived till the end. For each probability configuration of $U$ we repeat the simulation of $U$, the estimation of the outcome effect, selection effect and the IPW-Cox treatment effects $M=100$ times and obtain the average of these 100 simulations. The total variance of these averages can be estimated from (see Ichino et al. (2008)):

$$
\operatorname{Var}_{f}=\frac{1}{M} \sum_{m=1}^{M} s_{m}^{2}+\frac{M-1}{M(M-1)} \sum_{m=1}^{M}\left(\hat{f}_{m}-\bar{f}\right)^{2}
$$

with $f \in\{\omega, \xi$, ATE, ATT, ATU $\}$ of each pairwise education comparison, $\hat{f}_{m}$ is the estimated $f$ in each simulation sample $m$ and $s_{m}^{2}$ is its estimated variance.

Table 5 shows the outcome and selection effects for the case in which $U$ follows the distribution of each of the categories of the IQ-test (the outcome and selection effects based on the distribution of the other covariates are given in Table B.7 in Appendix B). The estimated outcome effect ranges from -4.5 to 0.4 and the selection effects range from -2.8 to 3.9. Only a few outcome effects are significant, but most of the selection effects are.

The IPW estimates using a Cox model that includes the additional variable $U$ (along with the IQscore) given in Table 6 show that the impact of education on mortality changes slightly with respect to the baseline (not including $U$ ) in some cases, but none of these changes are significant. The ATU of education on the mortality rate for men with only primary education is, contrary to the baseline, only significant when $U$ follows a distribution close to the middle IQ-values. 
Table 5: Sensitivity analysis propensity score with IQ as selection variable: outcome and selection effects

\begin{tabular}{|c|c|c|c|c|c|c|}
\hline & \multicolumn{2}{|c|}{$\begin{array}{l}\text { Primary to } \\
\text { lower vocational }\end{array}$} & \multicolumn{2}{|c|}{$\begin{array}{c}\text { Lower vocational to } \\
\text { lower secondary }\end{array}$} & \multicolumn{2}{|c|}{$\begin{array}{c}\text { Lower secondary to } \\
\text { higher }\end{array}$} \\
\hline & $\omega$ & $\xi$ & $\omega$ & $\xi$ & $\omega$ & $\xi$ \\
\hline IQ-test & & & & & & \\
\hline 1 (highest) & $\begin{array}{l}-4.26 \\
(11.99)\end{array}$ & $\begin{array}{l}3.94^{* *} \\
(0.56)\end{array}$ & $\begin{array}{c}-0.44^{* *} \\
(0.15)\end{array}$ & $\begin{array}{l}1.30^{* *} \\
(0.07)\end{array}$ & $\begin{array}{l}-0.16 \\
(0.09)\end{array}$ & $\begin{array}{l}1.58^{* *} \\
(0.06)\end{array}$ \\
\hline 2 & $\begin{array}{c}-0.43 \\
(0.29)\end{array}$ & $\begin{array}{l}2.27^{* *} \\
(0.12)\end{array}$ & $\begin{array}{r}-0.14^{+} \\
(0.07)\end{array}$ & $\begin{array}{l}0.89^{* *} \\
(0.04)\end{array}$ & $\begin{array}{c}-0.08 \\
(0.07)\end{array}$ & $\begin{array}{c}-0.42^{* *} \\
(0.05)\end{array}$ \\
\hline 4 & $\begin{array}{c}-0.05 \\
(0.10)\end{array}$ & $\begin{array}{c}-0.29^{* *} \\
(0.06)\end{array}$ & $\begin{array}{c}0.08 \\
(0.07)\end{array}$ & $\begin{array}{c}-1.32^{* *} \\
(0.06)\end{array}$ & $\begin{array}{c}0.28^{+} \\
(0.11)\end{array}$ & $\begin{array}{c}-2.55^{* *} \\
(0.26)\end{array}$ \\
\hline 5 & $\begin{array}{c}0.12 \\
(0.09)\end{array}$ & $\begin{array}{l}-1.70^{* *} \\
(0.07)\end{array}$ & $\begin{array}{c}0.20^{+} \\
(0.09)\end{array}$ & $\begin{array}{c}-1.95^{* *} \\
(0.12)\end{array}$ & $\begin{array}{c}0.40 \\
(0.23)\end{array}$ & $\begin{array}{c}-2.84^{* *} \\
(0.68)\end{array}$ \\
\hline 6 (lowest) & $\begin{array}{c}0.15 \\
(0.13)\end{array}$ & $\begin{array}{l}-2.74^{* *} \\
(0.18)\end{array}$ & $\begin{array}{c}0.20 \\
(0.32)\end{array}$ & $\begin{array}{l}-2.22^{* *} \\
(0.50)\end{array}$ & $\begin{array}{c}-0.22 \\
(5.41)\end{array}$ & $\begin{array}{c}-0.79 \\
(1.12)\end{array}$ \\
\hline
\end{tabular}

Based on adding $U$ to propensity score with probabilities of $U$ from observed probabilities of IQ-categories.

No effect would give $\omega=0$ and $\xi=0 .{ }^{+} p<0.05$ and ${ }^{* *} p<0.01$

Table 6: Sensitivity of impact of education

\begin{tabular}{|c|c|c|c|c|c|c|c|c|c|}
\hline & \multicolumn{3}{|c|}{$\begin{array}{l}\text { Primary to } \\
\text { lower vocational }\end{array}$} & \multicolumn{3}{|c|}{$\begin{array}{l}\text { Lower vocational to } \\
\text { lower secondary }\end{array}$} & \multicolumn{3}{|c|}{$\begin{array}{l}\text { Lower secondary to } \\
\text { higher }\end{array}$} \\
\hline & ATE & ATT & ATU & ATE & ATT & ATU & ATE & ATT & ATU \\
\hline original & $\begin{array}{c}-0.026 \\
(0.056)\end{array}$ & $\begin{array}{c}0.024 \\
(0.070)\end{array}$ & $\begin{array}{r}-0.108^{+} \\
(0.050)\end{array}$ & $\begin{array}{c}0.029 \\
(0.035)\end{array}$ & $\begin{array}{c}0.016 \\
(0.037)\end{array}$ & $\begin{array}{c}0.029 \\
(0.039)\end{array}$ & $\begin{array}{c}-0.091 \\
(0.061)\end{array}$ & $\begin{array}{c}-0.090 \\
(0.050)\end{array}$ & $\begin{array}{r}-0.088 \\
(0.076)\end{array}$ \\
\hline IQ-test & & & & & & & & & \\
\hline 1 (highest) & $\begin{array}{c}0.040 \\
(0.322)\end{array}$ & $\begin{array}{c}0.098 \\
(0.401)\end{array}$ & $\begin{array}{c}-0.085 \\
(0.052)\end{array}$ & $\begin{array}{c}0.064 \\
(0.038)\end{array}$ & $\begin{array}{c}0.070 \\
(0.044)\end{array}$ & $\begin{array}{c}0.049 \\
(0.042)\end{array}$ & $\begin{array}{c}-0.019 \\
(0.091)\end{array}$ & $\begin{array}{c}-0.035 \\
(0.070)\end{array}$ & $\begin{array}{c}-0.011 \\
(0.118)\end{array}$ \\
\hline 2 & $\begin{array}{l}0.108 \\
(0.183)\end{array}$ & $\begin{array}{c}0.198 \\
(0.250)\end{array}$ & $\begin{array}{c}-0.079 \\
(0.057)\end{array}$ & $\begin{array}{c}0.050 \\
(0.038)\end{array}$ & $\begin{array}{c}0.043 \\
(0.042)\end{array}$ & $\begin{array}{l}0.046 \\
(0.044)\end{array}$ & $\begin{array}{c}-0.080 \\
(0.065)\end{array}$ & $\begin{array}{c}-0.098 \\
(0.051)\end{array}$ & $\begin{array}{r}-0.069 \\
(0.082)\end{array}$ \\
\hline 4 & $\begin{array}{c}-0.026 \\
(0.057)\end{array}$ & $\begin{array}{c}0.023 \\
(0.072)\end{array}$ & $\begin{array}{r}-0.104^{+} \\
(0.051)\end{array}$ & $\begin{array}{c}0.062 \\
(0.042)\end{array}$ & $\begin{array}{c}0.029 \\
(0.040)\end{array}$ & $\begin{array}{c}0.079 \\
(0.055)\end{array}$ & $\begin{array}{c}-0.087 \\
(0.182)\end{array}$ & $\begin{array}{c}-0.068 \\
(0.053)\end{array}$ & $\begin{array}{c}-0.096 \\
(0.231)\end{array}$ \\
\hline 5 & $\begin{array}{c}0.031 \\
(0.079)\end{array}$ & $\begin{array}{c}0.079 \\
(0.104)\end{array}$ & $\begin{array}{r}-0.050 \\
(0.080)\end{array}$ & $\begin{array}{c}0.064 \\
(0.048)\end{array}$ & $\begin{array}{c}0.036 \\
(0.039)\end{array}$ & $\begin{array}{c}0.076 \\
(0.070)\end{array}$ & $\begin{array}{c}-0.095 \\
(0.076)\end{array}$ & $\begin{array}{c}-0.082 \\
(0.051)\end{array}$ & $\begin{array}{r}-0.098 \\
(0.100)\end{array}$ \\
\hline 6 (lowest) & $\begin{array}{c}-0.004 \\
(0.075)\end{array}$ & $\begin{array}{c}0.044 \\
(0.080)\end{array}$ & $\begin{array}{c}-0.085 \\
(0.126)\end{array}$ & $\begin{array}{c}0.035 \\
(0.039)\end{array}$ & $\begin{array}{c}0.018 \\
(0.037)\end{array}$ & $\begin{array}{c}0.039 \\
(0.049) \\
\end{array}$ & $\begin{array}{c}-0.091 \\
(0.061) \\
\end{array}$ & $\begin{array}{c}-0.089 \\
(0.050) \\
\end{array}$ & $\begin{array}{r}-0.088 \\
(0.076) \\
\end{array}$ \\
\hline
\end{tabular}

Based on adding $U$ to propensity score with probabilities of $U$ from observed for comprehensive IQ-test. 


\section{Mediation analysis for the mortality hazard rate}

An alternative to assuming that cognitive ability at age 18 is a proxy for early childhood cognitive ability is to assume that education raises cognitive ability and that part of the impact of education on mortality runs through increased cognitive ability. In this section we discuss a model in which cognitive ability at age 18 mediates the impact of education on mortality. Mediation analysis aims to unravel the underlying causal mechanism into an effect running through changes of an intermediate variable, the mediator, and through other pathways. The counterfactual notation used in Section 3 for average treatment effects can be extended to define causal mediation, (see Huber 2014). We are particularly interested in the mediating effect of cognitive ability on mortality. It has been proven that high levels of cognitive ability is positively associated with high education, (Ceci 1991; Hansen et al. 2004; Carlsson et al. 2015). Note that this does not rule out that early childhood cognitive ability influences the education choice. We use $Q_{i}$ to denote the observed cognitive ability (IQ-score), which is measured around age 18 when the men had their military examination and after they had completed secondary schooling. The mediation model we assume is illustrated by the DAG in Figure 5

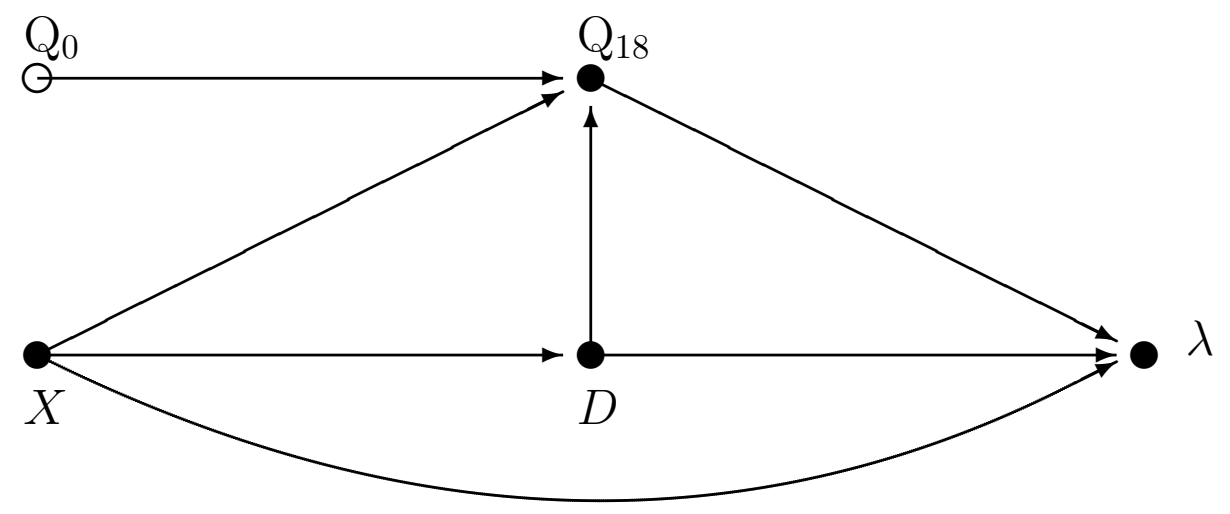

Figure 5: Directed acyclic graph of mediation through $\mathrm{Q}_{18}$ conditional on $X$

Traditionally, causal mediation analysis has been formulated with the framework of linear structural models (Baron and Kenny 1986). Recent papers have placed causal mediation analysis within the counterfactual/potential outcomes framework (Imai et al. 2010; Imai et al. 2011; Huber 2014). In the previous section the potential outcome was solely a function of the treatment, e.g. education choice, but in mediation analysis the potential outcomes also depend on the mediator. Because cog- 
nitive ability can be affected by the education attained ${ }^{8}$, there exist two potential values, $Q_{i}(1)$ and $Q_{i}(0)$, only one of which will be observed, i.e. $Q_{i}=D_{i} \cdot Q_{i}(1)+\left(1-D_{i}\right) \cdot Q_{i}(0)$. For example, if individual $i$ actually attained education level 1 , we would observe $Q_{i}(1)$ but not $Q_{i}(0)$. Next we use $\lambda_{i}(t \mid d, q(d))$ to denote the potential mortality hazard that would result from education equals $d$ and cognitive ability equals $q$. For example, in the conscription data, $\lambda_{i}(t \mid 1,110)$ represents the mortality hazard that would have been observed if individual $i$ had education level 1 and a measured IQ-score of 110. As before, we only observe one of the multiple hazards $\lambda_{i}=\lambda_{i}\left(t \mid D_{i}, Q_{i}\left(D_{i}\right)\right)$.

Because we base our treatment effect on (mixed) proportional hazard models, it is again natural to define the mediator effects proportionally. Abbring and van den Berg (2003) also define, in a different setting with a dynamic treatment, a proportional treatment effect for a duration outcome. In other non-linear settings, such as count data regression, a proportional treatment effect has been defined (Lee and Kobayashi 2001). We define the average effect of other pathways, depending on treatment status $d$ :

$$
\theta(d)=\frac{\mathrm{E}[\lambda(t \mid 1, Q(d))]}{\mathrm{E}[\lambda(t \mid 0, Q(d))]}
$$

This framework enables us to disentangle the underlying causal pathway from education to mortality into an effect of education through improvement of cognitive ability and an effect through other pathways. We assume conditional independence (given $X$ ) of the treatment and the mediator:

Assumption 3. Sequential ignorablility: $\left\{\lambda\left(t \mid d^{\prime}, q\right), Q(d)\right\} \perp D \mid X$ and $\lambda\left(t \mid d^{\prime}, q\right) \perp Q \mid D=d, X, \forall d, d^{\prime}=$ 0,1 and $q$ in the support of $Q$.

The first condition of Assumption 3 implies that, conditional on observed covariates $X$, no unobserved confounder exists that jointly affects the education choice, the cognitive ability and the mortality. The second condition implies that, conditional on observed covariates $X$ and the education attained, no unobserved confounder exists that jointly affects cognitive ability and mortality. Assumption 3 is a strong assumption and nonrefutable. We therefore carry out a set of sensitivity analyses to quantify the robustness of our empirical findings to violation of the sequential ignorability assumption based on an extension of the sensitivity analyses of the total IPW effect used in the previous section. We also have a common support restriction:

Assumption 4. Common support mediator: $0<\operatorname{Pr}(D=1 \mid Q, X)<1$.

\footnotetext{
${ }^{8}$ For example, Jones et al. (2011) discuss how performance in IQ tests could be influenced by coaching received by primary school pupils to prepare them for entrance tests for secondary school.
} 
In addition we assume:

Assumption 5. Proportional mediator effect: $\lambda(t \mid 1, Q(d))=e^{\theta(d)} \lambda(t \mid 0, Q(d))$.

This is equivalent to assuming that the effect of the treatment, $D$, is not moderated by the value of the mediator. Thus, we assume no interaction effect, $D \cdot Q$, in the hazard. Note that Assumption 5 does not rule out an MPH model. It only assumes that the unobserved heterogeneity is independent of the treatment $D$ (as before) and the mediator $Q$. Huber (2014) makes the same assumptions for identification of the direct and indirect effects in a 'standard' mean difference outcome model. This leads to the following identification theorem for the effect of a treatment on the hazard running through other pathways (holding the mediator constant):

\section{Theorem 1: Identification of other pathways effect $\theta(d)$.}

Under Assumptions 1 to 5 the other pathways effect is identified through a weighted Cox or MPH regression with weights:

$$
W(d)=\frac{\operatorname{Pr}(D=d \mid Q, X)}{\operatorname{Pr}(D=d \mid X)}\left(\frac{D}{\operatorname{Pr}(D=1 \mid Q, X)}+\frac{1-D}{\operatorname{Pr}(D=0 \mid Q, X)}\right)
$$

with weight $W(d)$ for $\theta(d)$, for $d=0,1$.

(See Appendix A for the proof.)

The 'total effect' of education on the mortality rate, from an IPW estimation in which the mediator is excluded from the propensity score, can be decomposed into an effect of education running through the mediator $\eta(\cdot)$ and an effect of education running through other pathways $\theta(\cdot)$ :

$$
\begin{aligned}
\frac{\lambda(t \mid D=1, Q(1))}{\lambda(t \mid D=0, Q(0))} & =\frac{\lambda(t \mid D=1, Q(1))}{\lambda(t \mid D=0, Q(1))} \cdot \frac{\lambda(t \mid D=0, Q(1))}{\lambda(t \mid D=0, Q(0))}=\exp (\theta(1)+\eta(0)) \\
& =\frac{\lambda(t \mid D=1, Q(1))}{\lambda(t \mid D=1, Q(0))} \cdot \frac{\lambda(t \mid D=1, Q(0))}{\lambda(t \mid D=0, Q(0))}=\exp (\eta(1)+\theta(0))
\end{aligned}
$$

The effect running through other pathways (holding the mediator constant) can be estimated solving (5), for a Cox model, or (7), for a MPH model, using $W(d)$ from (12) as weights. The effect running through the mediator can be obtained from the log-difference of the estimated total and the estimated direct effect, using (13) or (14). The first effect represent the effect of education on the mortality hazard while holding cognitive ability constant at the level that would have been realized for chosen education level $d$. The second effect represents the effect education on mortality if one changes cognitive ability 
from the value that would have been realized for education level 0 to the value that would have been observed for education level 1, while holding the education level at level $d$.

For estimation we use normalized versions of the sample implied by the weights in (12), such that the weights in either treatment or control groups add up to unity, as advocated earlier. We estimate the additional propensity scores conditional on the pre-treatment covariates and the mediator, $\operatorname{Pr}\left(D=1 \mid X_{i}, Q_{i}\right)$, by probit specifications.

To estimate the average treatment effect on the treated (ATT) through other pathways, we need to weight the contribution of $W(1)$ by the propensity score $\hat{p}\left(X_{i}\right)$. Similarly, if we want to estimate the average direct effect on the untreated (ATU), we reweight the contribution of $W(0)$ by one minus the propensity score. ${ }^{9}$ Note that the ATT and ATU weights for these effects are exactly the same as the ATT and ATU weights for the total IPW effect when including IQ in the propensity score.

A nice feature of Theorem 1 is that it is straightforward to implement, and only involves estimation of two propensity scores and plugging them into standard mixed proportional hazard estimation. No parametric restriction is imposed on the model of the mediator. Tchetgen Tchetgen (2013) also defines mediation analysis in (Cox) proportional hazard models. His method implies estimating a regression model for the mediator conditional on the treatment and pre-treatment covariates, $f(Q \mid D, X)$, and it is more difficult to formulate a suitable model for the mediator than for the propensity score.

\subsection{Empirical results for the mediation analysis}

In Table 7 we present the decomposition of the effects of education on the mortality rate. The effect of education through other pathways is only significant for the highest education group, about two-third of the mortality reduction for men moving from lower secondary to higher education runs through noncognitive ability effects, such as, for example, an increase in income. For the lowest education group the impact of education on mortality mainly runs through the increase in cognitive ability induced by the additional education. For these less educated men $90 \%$ of the reduction in mortality is explained by the mediation effect of cognitive ability. Focusing on the treatment effect on the untreated, the effect of improving education on the mortality hazard for those with the lower education level, the effect of education for the lowest education group runs through other pathways and explains about $50 \%$ of the reduction. Note that the direct ATT and ATU of education are exactly equal to the ATT and ATU in a selection model with the IQ-measures in the propensity score. Accounting for unobserved heterogeneity in the mortality hazard, through the Gamma-Gompertz specification, only affects the estimates for the highest education group, shown in the lower panel of Table 7 .

\footnotetext{
${ }^{9}$ Of course, only $\theta(1)$ is relevant when interested in treatment on the treated and only $\theta(0)$ when interested in the treatment on the untreated.
} 
Table 7: Decomposition of the educational gradient on the mortality rate, into an effect running though cognitive ability and running through other pathways

\begin{tabular}{|c|c|c|c|c|c|c|}
\hline & \multicolumn{4}{|c|}{ Average treatment effect (ATE) } & \multirow{2}{*}{\multicolumn{2}{|c|}{$\begin{array}{l}\text { ATT } \\
\text { other pathways }\end{array}$}} \\
\hline & \multicolumn{2}{|c|}{ other pathways } & \multicolumn{2}{|c|}{ cognitive ability } & & \\
\hline & $\theta(1)$ & $\theta(0)$ & $\eta(0)$ & $\eta(1)$ & $\theta(1)$ & $\theta(0)$ \\
\hline Cox & & & & & & \\
\hline $\begin{array}{l}\text { Primary to } \\
\text { lower vocational }\end{array}$ & $\begin{array}{c}-0.022 \\
(0.068)\end{array}$ & $\begin{array}{c}-0.070 \\
(0.048)\end{array}$ & $\begin{array}{c}-0.164^{+} \\
(0.078)\end{array}$ & $\begin{array}{c}-0.116 \\
(0.062)\end{array}$ & $\begin{array}{c}0.024 \\
(0.070)\end{array}$ & $\begin{array}{r}-0.108^{+} \\
(0.051)\end{array}$ \\
\hline Lower vocational to & 0.038 & 0.036 & -0.090 & -0.088 & 0.016 & 0.029 \\
\hline lower secondary & $(0.035)$ & $(0.038)$ & $(0.047)$ & $(0.049)$ & $(0.037)$ & $(0.039)$ \\
\hline $\begin{array}{r}\text { Lower secondary to } \\
\text { higher }\end{array}$ & $\begin{array}{r}-0.124^{+} \\
(0.050)\end{array}$ & $\begin{array}{r}-0.079 \\
(0.069)\end{array}$ & $\begin{array}{r}-0.066 \\
(0.068)\end{array}$ & $\begin{array}{r}-0.110 \\
(0.083)\end{array}$ & $\begin{array}{r}-0.090 \\
(0.050)\end{array}$ & $\begin{array}{r}-0.086 \\
(0.076)\end{array}$ \\
\hline Gamma-Gompertz & & & & & & \\
\hline $\begin{array}{l}\text { Primary to } \\
\text { lower vocational }\end{array}$ & $\begin{array}{c}-0.021 \\
(0.068)\end{array}$ & $\begin{array}{r}-0.069 \\
(0.048)\end{array}$ & $\begin{array}{r}-0.164^{+} \\
(0.079)\end{array}$ & $\begin{array}{r}-0.116 \\
(0.062)\end{array}$ & $\begin{array}{c}0.025 \\
(0.070)\end{array}$ & $\begin{array}{r}-0.108^{+} \\
(0.051)\end{array}$ \\
\hline Lower vocational to & 0.038 & 0.037 & -0.090 & -0.089 & 0.016 & 0.032 \\
\hline lower secondary & $(0.035)$ & $(0.040)$ & $(0.047)$ & $(0.051)$ & $(0.037)$ & $(0.042)$ \\
\hline $\begin{array}{r}\text { Lower secondary to } \\
\text { higher }\end{array}$ & $\begin{array}{r}-0.149^{+} \\
(0.061)\end{array}$ & $\begin{array}{r}-0.094 \\
(0.081)\end{array}$ & $\begin{array}{r}-0.067 \\
(0.080)\end{array}$ & $\begin{array}{r}-0.123 \\
(0.097)\end{array}$ & $\begin{array}{r}-0.104 \\
(0.060)\end{array}$ & $\begin{array}{r}-0.104 \\
(0.088)\end{array}$ \\
\hline
\end{tabular}

${ }^{+} p<0.05$ and ${ }^{* *} p<0.01$

To account for possible misspecification of the propensity scores we also estimate doubly robust estimators of the models, including the covariates both in the propensity score and in the hazard regression. Including regression covariates hardly changes the estimates (a table with detailed results can be found in Appendix B).

\subsection{Sensitivity analyses}

For identification of the mediation effects we impose sequential ignorability (Assumption 3). We extend the sensitivity analyses in Section 4.1 to assume that conditional on the binary (unobserved) factor the following two conditions hold (i) $\left\{\lambda\left(t \mid d^{\prime}, m\right), Q(d)\right\} \perp D \mid X, U$ and (ii) $\lambda\left(t \mid d^{\prime}, q\right) \perp Q \mid D=d, X, U$ for $\forall d, d^{\prime}=0,1$ and $q$ in the support of $Q$. These conditions lead to one of two following probabilities that define the distribution of $U$ :

$$
\begin{aligned}
& p_{q j}^{\delta}=\operatorname{Pr}(U=1 \mid Q=q, \delta=j, X)=\operatorname{Pr}(U=1 \mid Q=q, \delta=j) \\
& p_{q i}^{Q}=\operatorname{Pr}(U=1 \mid Q=q, D=i, X)=\operatorname{Pr}(U=1 \mid Q=q, D=i)
\end{aligned}
$$

where $q=1, \ldots, 6$ the six possible values of the IQ-tests.

As in the previous sensitivity analyses we define the outcome-effect as $\omega$, the coefficient of $U$ in a Cox model for the control group $(D=0)$ using $U, X$ and $Q$ as covariates, the selection effect $\xi$, the coefficient of $U$ in a logit model on the treatment assignment $(D)$ using $U$ and $X$ as covariates. A 
new measure, the mediator-effect, is $\psi$, the coefficient of $U$ in an ordered logit model on the IQ-test values for the control group using $U$ and $X$ as covariates.

The configurations of $p_{q j}^{\delta}$ and $p_{q i}^{Q}$ are chosen such that they mimic the probability that a binary variable is equal to one conditional on $Q$ and $\delta$ or $Q$ and $D$ for each included binary variable. For each configuration we simulate $U 100$ times, calculate the outcome and selection effects and the implied IPW impact of education on the mortality rate. For all these calculation the value of the IQ-test is now also included. These outcome, selection and mediator effects are rather small and only a few are significantly different from zero. Next we re-estimate the decomposition of the effect of education using an IPW Cox including $U$ in the propensity score. None of the assumed distributions of the unobserved confounder $U$ leads to a substantial change in the estimated decomposition of the effects of education on mortality. ${ }^{10}$

\section{Implied gain in life-expectancy}

From the Gompertz-hazards we can estimate the median survival age of the recruits and their post 18 life expectancy. The median survival age is the age at which half of the people have died (conditional on survival up to age 18). Assuming that the estimated Gompertz hazard holds, the life expectancy at age $t_{0}=18$ can be very well approximated by (see Lenart (2014)):

$$
\mathrm{LE}\left(t_{0}\right)=-\exp \left(e^{\alpha_{0}+\alpha_{1} t_{0}}\right)\left(\alpha_{0}-\ln \left(\alpha_{1}\right)+\alpha_{1} t_{0}+0.5772\right) / \alpha_{1}
$$

where 0.5772 is the Euler constant. For the unadjusted Gompertz model the estimated remaining life expectancies are 59.8 (primary); 62.5 (lower vocational); 63.3 (lower secondary) (63.8 based on last two education groups) and 66.4 (higher). Leading to educational gains of 2.6, 0.8 and 2.6 in life expectancy. The median survival ages are 80.1 (primary); 82.8 (lower vocational); 83.6 (lower secondary) (84.6) and 86.8 (higher). Thus leading to the same educational gains.

In Table 8 we report the gains in life expectancy. Based on the IPW estimates with IQ included as a selection variable, in the upper panel of the table. From primary to lower vocational education he would have gained 0.3 additional years (and his median age also would have improved by 0.3 years). If an individual had improved from lower vocational to lower secondary there would be a loss in life expectancy of 0.3 years. The gain in life expectancy if an individual had improved his education from lower secondary to higher education is 1.1 years. If the men with primary education had increased their education to lower vocational they would have gained 1.3 additional years of living (ATU). For the other two groups the ATTs and ATUs are close to the ATEs.

\footnotetext{
${ }^{10}$ The full tables of results can be found in Table B.10 to B.13 in Appendix B.
} 
The lower panel of Table 8 reports the gains in life expectancy based on the mediation analysis and decomposes the effects of education into an effect running through cognitive ability and an effect running through other pathways. Based on the IPW estimates we can conclude that if an individual had improved his education from primary to lower vocational he would have gained 2.1 additional years (and his median age also would have improved by 2.1 years), of which 1.3 years are attributable to an increases in cognitive ability induced by the higher education and 0.6 years to other changes induced by higher education (1.9 and 0.2 for those who have vocational education). If an individual had improved from lower vocational to lower secondary the gain in life expectancy is 0.6 years (1.0 attributable to an increase in cognitive ability and an negative impact of other changes). The gain in life expectancy if an individual had improved his education from lower secondary to higher education is 2.2 years. For those who attained higher education this gain in life expectancy is mainly attributable to the effect of education on other pathways (1.5 years), while for those with lower secondary education the effect running through an increase in cognitive ability is larger (1.3 years) than effect running through other pathways.

Table 8: Gain in life expectancy

\begin{tabular}{l|ccc}
\hline \hline & $\begin{array}{c}\text { Primary to } \\
\text { lower vocational }\end{array}$ & $\begin{array}{c}\text { Lower vocational to } \\
\text { lower secondary }\end{array}$ & $\begin{array}{c}\text { Lower secondary to } \\
\text { higher }\end{array}$ \\
\hline Unadjusted & 2.7 & 0.8 & 2.6 \\
\hline & & IPW including IQ & \\
ATE & 0.3 & -0.3 & 1.1 \\
ATT & -0.3 & -0.2 & 1.1 \\
ATU & 1.3 & -0.3 & 1.0 \\
\hline & & IPW mediation & \\
ATE total & 2.1 & 0.6 & 2.2 \\
Other pathways & & & \\
ATE $\theta(1)$ & 0.2 & -0.4 & 0.9 \\
ATE $\theta(0)$ & 0.8 & -0.4 & 1.1 \\
ATT $\theta(1)$ & -0.3 & -0.2 & 1.0 \\
ATU $\theta(0)$ & 1.3 & -0.3 & 0.7 \\
Cognitive ability & & & 1.3 \\
ATE $\eta(0)$ & 1.9 & 1.0 & \\
ATE $\eta(1)$ & 1.3 & 1.0 & \\
\hline
\end{tabular}




\section{Discussion}

A large literature documents that higher levels of education are positively associated with a longer life. Possible mechanisms include occupational risks, health behavior, the ability to process information and cognitive ability (Cutler and Lleras-Muney 2008). It is commonly acknowledged that education and cognitive ability are correlated. Cognitive ability may cause differences in educational outcomes or education may cause cognitive ability differences. Most of the economics literature on the causal effect of education on health focuses on accounting for endogenous selection into education due to confounding third factors, such as cognitive ability, either by exploiting natural experiments in education due to changes in compulsory schooling laws (Mazumder 2012) or by defining a structural model (Conti et al. 2010; Bijwaard et al. 2015). The estimates based on natural experiments find little to no effect of education on health, while the studies based on structural models find that around half of the difference in health by education is due to selection. An alternative perspective is that cognitive ability is part of the causal pathway from education to mortality. It has been proven that high scores on intelligence tests are positively associated with schooling level, (Ceci 1991; Hansen et al. 2004; Carlsson et al. 2015).

In this paper we show that making different assumptions about the place of cognitive ability, measured at late adolescence, in the causal path from education to mortality has little effect on the estimated impact of education on mortality. We estimate and compare two models. In the first model we assume that IQ measured at age 18 is a proxy for early childhood cognitive ability and is an important factor determining the education choice. In the second model we assume that this cognitive ability is affected by educational attainment and has a mediating effect on the mortality difference across education groups. For both models we developed an inverse probability weighting (IPW) method for hazard models to estimate the impact of education on the mortality rate. We use conscription data of Dutch men born in 1944-1947 who were examined for military service between 1961-1965, and linked to national death records, in which we identified four education groups. Using the IPW methods we estimate, for each adjacent education group, the impact of improving education on the mortality risk. In the first model we obtain the total impact of education on mortality, while in the second model we decompose the impact of education into an effect running through cognitive ability and an effect running through other pathways.

The results show that controlling for cognitive ability, either as a selection factor or as a mediating factor, leaves only limited evidence of a educational gain in mortality. In the selection model, the only significant result we find is that men with only primary education would have reduced their mortality rate by $11 \%$ if they had improved their education to lower vocational (Average treatment on the 
untreated). This amounts to 1.3 additional years of life.

When accounting for cognitive ability as a mediator in the causal pathway from education to mortality, for men with primary school we find that only the effect of education running through an increase in cognitive ability significantly reduces the mortality risk (about $15 \%$ reduction in the mortality rate), which is equivalent to 1.9 years longer life expectancy. For the highest education group only the effect of education running through other pathways, such as income effects of education, is significant (about 12\% reduction in the mortality rate), leading to 1.5 additional years of life.

When accounting for cognitive ability as a mediator in the causal pathway from education to mortality, the direct effect of education is only significant for highest education group (about $12 \%$ reduction in the mortality rate), leading to 1.5 additional years of life. For men with primary school we find a significant indirect effect of cognitive ability, through education, on mortality risk (about $15 \%$ reduction in the mortality rate), which is equivalent to 1.9 years longer life expectancy.

A limitation of our data, based on military entrance examination, is that we only observe men and no information on women is available. Bijwaard et al. (2015) found that educational gains for women appear to be higher than for men, in spite of the higher survival difference of women with lower versus higher education. These findings are based on much smaller numbers than the current study however and therefore need to be interpreted with caution. Another issue is that in the 1960s a major change occurred in the education system in the Netherlands and some of the specific education strata in this study no longer exist. In addition, the percentage of people with more than six years of post-primary school education is currently much higher compared to the past. These changes are not likely to affect our general conclusion that increased education only has a small effect on survival, but further long term studies will be needed to quantify these effects for contemporary school types. The issue of reverse causality that early childhood health affects educational attainment might distort our analyses (Case et al. 2005; Currie 2009). We have no information about childhood health status, which prevents us from investigating the possibility of reverse causality from health to education in our sample.

\section{References}

Aalen, O. O., O. Borgan, and H. K. Gjessing (2009). Survival and Event History Analysis. New York: Springer-Verlag.

Abbring, J. H. and G. J. van den Berg (2003). The non-parametric identification of treatment effects in duration models. Econometrica 71, 1491-1517.

Albouy, V. and L. Lequien (2009). Does compulsory education lower mortality? Journal of Health Economics 28(1), 155-168.

Andersen, P. K. and O. Borgan (1985). Counting process models for life history data: A review. 
Scandinavian Journal of Statistics 12, 97-158.

Andersen, P. K., O. Borgan, R. D. Gill, and N. Keiding (1993). Statistical Models Based on Counting Processes. New York: Springer-Verlag.

Auld, M. C. and N. Sidhu (2005). Schooling, cognitive ability and health. Health Economics 14(10), $1019-1034$.

Austin, P. C. (2014). A tutorial on the use of propensity score methods with survival or time-toevent outcomes: Reporting measures of effect similar to those used in randomized experiments. Statistics in Medicine 33, 1242-1258.

Baron, R. M. and D. A. Kenny (1986). The moderator-mediator variable distinction in social psychological research: Conceptual, strategic, and statistical considerations. Journal of Personlaity and Social Psychology 51, 1173-1182.

Basu, A., A. M. Jones, and P. Rosa Dias (2014). Long-term effects of school quality on health and lifestyle: Evidence from comprehensive schooling reforms in England. Working paper no. 20811, NBER.

Batty, G. and G. David (2004). Early life intelligence and adult health. British Medical Journal 329(7466), 585-586.

Batty, G., G. David, I. J. Deary, and L. S. Gottfredson (2007). Premorbid (early life) IQ and later mortality risk: Systematic review. Annals of Epidemiology 17(4), 278-288.

Bijwaard, G. E. and H. van Kippersluis (2015). Efficiency of health investment: Education or intelligence? Discussion Paper 15-004, Tinbergen Institute.

Bijwaard, G. E., H. van Kippersluis, and J. Veenman (2015). Education and health: the role of cognitive ability. Journal of Health Economics 42, 29-43.

Bruggink, J. W. (2009). Ontwikkelingen in de (gezonde) levensverwachting naar opleidingsniveau. Bevolkingstrends 57(4), 71-74.

Caliendo, M. and S. Kopeinig (2008). Some practical guidance for the implementation of propensity score matching. Journal of Economic Surveys 22, 31-72.

Calvin, C. M., I. J. Deary, C. Fenton, B. A. Roberts, G. Der, N. Leckenby, and G. D. Batty (2011). Intelligence in youth and all-cause-mortality: Systematic review with meta-analysis. International Journal of Epidemiology 40(3), 626-640.

Carlsson, M., G. B. Dahl, B. Öckert, and D.-O. Rooth (2015). The effect of schooling on cognitive skills. The Review of Economics and Statistics 97, 533-547.

Case, A., A. Fertig, and C. Paxson (2005). The lasting impact of childhood health and circumstance. Journal of Health Economics 24, 365-389.

Ceci, S. J. (1991). How much does schooling influence general intelligence and its cognitive components? a reassessment of the evidence. Developmental Psychology 27, 703-722.

Clark, D. and H. Royer (2013). The effect of education on adult mortality and health: Evidence from Britain. American Economic Review 103(6), 2087-2120.

Cole, S. R. and M. A. Hernán (2004). Adjusted survival curves with inverse probability weights. Computer Methods and Programs in Biomedicine 75, 45-49.

Conti, G. and J. J. Heckman (2010). Understanding the early origins of the education-health gradient: A framework that can also be applied to analyze gene-environment interactions. Perspectives on Psychological Science 5, 585-605.

Conti, G., J. J. Heckman, and S. Urzua (2010). The education-health gradient. American Economic Review 100, 234-238. 
Currie, J. (2009). Healthy, wealthy, and wise: Socioeconomics status, poor health in childhood, and human capital development. Journal of Economic Literature 41, 87-122.

Cutler, D. and A. Lleras-Muney (2008). Education and health: Evaluating theories and evidence. In J. S. House, R. F. Schoeni, G. A. Kaplan, and H. Pollack (Eds.), Making Americans Healthier: Social and Economic Policy as Health Policy. New-York: Russell Sage Foundation.

Deary, I. J. and W. Johnson (2010). Intelligence and education: causal perceptions drive analytic processes and therefore conclusions. International Journal of Epidemiology 39, 1362-1369.

Doob, L. J. (1953). Stochastic Processes. New York: Wiley.

Doornbos, G. and D. Kromhout (1990). Educational level and mortality in a 32-year follow-up study of 18-year-old men in the Netherlands. International Journal of Epidemiology 19, 374-379.

Ekamper, P., F. van Poppel, A. D. Stein, and L. H. Lumey (2014). Independent and additive association of prenatal famine exposure and intermediary life conditions with adult mortality between age 18-63 years. Social Science \& Medicine 119, 232-239.

Feng, P., X.-H. Zhou, Q.-M. Zou, M.-Y. Fan, and Z.-S. Li (2012). Generalized propensity score for estimating the average treatment effect of multiple treatments. Statistics in Medicine 31, 681-697.

Fletcher, J. M. (2015). New evidence of the effects of education on health in the US: Compulsory schooling laws revisited. Social Science \& Medicine 127, 101-107.

Gavrilov, L. A. and N. S. Gavrilova (1991). The Biology of Life Span: A Quantitative Approach. New York: Harwood Academic Publisher.

Grossman, M. (2015). The relationship between health and schooling: What's new? Nordic Journal of Health Economics 3, 7-17.

Hansen, K. T., J. J. Heckman, and K. J. Mullen (2004). The effect of schooling and ability on achievement test scores. Journal of Econometrics 121, 39-98.

Hartog, J. and H. Oosterbeek (1998). Health, wealth, and happiness: Why pursue higher education? Economic Education Review 17, 245-256.

Hirano, K., G. W. Imbens, and G. Ridder (2003). Efficient estimation of average treatment effects using the estimated propensity score. Econometrica 71, 1161-1189.

Huber, M. (2014). Identifying causal mechanisms (primarily) based on inverse probability weighting. Journal of Applied Econometrics 29, 920-943.

Ichino, A., F. Mealli, and T. Nannicini (2008). From temporary help jobs to permanent employment: What can we learn from matching estimators and their sensitivity? Journal of Applied Econometrics 23, 305-327.

Imai, K., L. Keele, and D. Tingley (2010). A general approach to causal mediation analysis. Psychological Methods 15, 309-334.

Imai, K., L. Keele, D. Tingley, and T. Yamamoto (2011). Unpacking the black box of causality: Learning about causal mechanisms from experimental and observational studies. American Political Science Review 105, 765-789.

Imai, K. and D. A. van Dyk (2004). Causal inference with general treatment regimes: Generalizing the propensity score. Journal of the American Statistical Association 99, 854-866.

Imbens, G. W. (2004). Nonparametric estimation of average treatment effects under exogeneity. The Review of Economics and Statistics 86, 4-29.

Jones, A. M., N. Rice, and P. Rosa Dias (2011). Long-term effects of school quality on health and lifestyle: Evidence from comprehensive schooling reforms in England. Journal of Human Capital 5, 342-376. 
Jürges, H., E. Kruk and S. Reinhold (2013)., The Effect of Compulsory Schooling on Health: Evidence from Biomarkers. Journal of Population Economics 26, 645-672.

Kaestner, R. and K. Callison (2011). Adolescent cognitive and non-cognitive correlates of health. Journal of Human Capital 5(1), 29-69.

Kalbfleisch, J. D. and R. L. Prentice (2002). The Statistical Analysis of Failure Time Data, second edition. John Wiley and Sons.

Klein, J. P. and M. L. Moeschberger (1997). Survival Analysis: Techniques for Censored and Truncated Data. New York: Springer-Verlag.

Lechner, M. (2002). Some practical issues in the evaluation of heterogeneous labour market programmes by matching methods. Journal of the Royal Statistical Society: Series A 165, 59-82.

Lee, M.-J. and S. Kobayashi (2001). Proportional treatment effects for count response panel data: Effects of binary excercise on health care demand. Health Economics 10, 411-428.

Lenart, A. (2014). The moments of the Gompertz distribution and the maximum likelihood of its parameters. Scandinavian Actuarial Journal of the Institute of Actuaries 3, 255-277.

Lleras-Muney, A. (2005). The Relationship Between Education and Adult Mortality in the United States. Review of Economic Studies 72, 189-221.

Mazumder, B. (2008). Does education improve health: A reexamination of the evidence from compulsory schooling laws. Economic Perspectives 33, 2-16.

Mazumder, B. (2012). The effects of education on health and mortality. Nordic Economic Policy Review 1, 261-301.

McCartney, G., C. Collins, and M. Mackenzie (2013). What (or who) causes health inequalities: Theories, evidence and implications? Health Policy 113, 221-227.

Meghir, C., M. Palme, and E. Simeonova (2013). Education, cognition and health: Evidence from a social experiment. Working paper no. 19002, NBER.

Meyer, P.-A. (1963). Decomposition of supermartingales: The uniqueness theorem. Illinois Journal of Mathematics 7, 1-17.

Nannicini, T. (2007). A simulation-based sensitivity analysis for matching estimators. STATA Journal 7, 334-350.

Pearl, J. (2000). Causality: Models, Reasoning and Inference. New York: Cambridge University Press.

Pearl, J. (2012). The mediation formula: A guide to the assessment of causal pathways in nonlinear models. In C. Berzuini, P. Dawid, and L. Bernardinelli (Eds.), Causality: Statistical Perspectives and Applications, pp. 151-179. Chichester: John Wiley.

Ravelli, G. P., Z. A. Stein, and M. W. Susser (1976). Obesity in young men after famine exposure in utero and early pregnancy. New England Journal of Medicine 7, 349-354.

Robins, J. M. (1999). Marginal structural models versus structural nested models as tools for causal inference. In M. E. Halloran and D. Berry (Eds.), Statistical Models in Epidemiology, the Environment, and Clinical Trials, pp. 95-133. New York: Springer.

Robins, J. M., M. A. Hernán, and B. Brumback (2000). Marginal structural models and causal inference in epidemiology. Epidemiology 11, 550-560.

Robins, J. M. and A. Rotnitzky (1992). Recovery of information and adjustment for dependent censoring using surrogate markers. In N. Jewell, K. Dietz, and V. Farewell (Eds.), AIDS Epidemiology-Methodological Issues, pp. 297-331. Boston: Birkhäuser. 
Rosenbaum, P. and D. B. Rubin (1983). The central role of the propensity score in observational studies for causal effects. Biometrika 70, 41-55.

Rotnitzky, A. and J. M. Robins (1995). Semiparametric regression estimation in the presence of dependent censoring. Biometrika 82, 805-820.

Rubin, D. B. (1974). Estimating causal effects of treatments in randomized and non-randomized studies. Journal of Educational Psychology 66, 688-701.

Schröder, H. and H. B. G. Ganzeboom (2014). Measuring and modelling level of education in European societies. European Sociological Review 47(9), 119-136.

Tchetgen Tchetgen, E. J. (2013). Inverse odds ratio-weighted estimation for causal mediation analysis. Statistics in Medicine 32, 4567-4580.

Therneau, T. and P. Grambsch (2000). Modeling Survival Data: Extending the Cox Model. New York: Springer-Verlag.

Van den Berg, G. J. (2001). Duration models: Specification, identification, and multiple duration. In J. Heckman and E. Leamer (Eds.), Handbook of Econometrics, Volume V, Chapter 55, pp. 3381-3460. Amsterdam: North-Holland.

Van Kippersluis, H., O. O'Donnell, and E. van Doorslaer (2011). Long run returns to education: Does schooling lead to an extended old age? Journal of Human Resources 46 (4), 695-721.

Vrooman, J. C. and J. Dronkers (1986). Changing educational attainment processes: Some evidence from the Netherlands. Sociology of Education 59(2), 69-78. 


\section{Appendix A Counting processes and proofs}

To prove the consistency and the properties of our estimation strategy we rely on counting process theory for duration models. In a Cox-model the waiting time to some event $T$ has a conditional distribution given observed $X$, treatment $D$ and mediator $Q$ with hazard rate

$$
\lambda(t \mid D, X, Q)=\lambda_{0}(t) e^{\beta^{\prime} X+\gamma D}
$$

The cdf and pdf of the distribution of the duration $T$ can be expressed as functions of the hazard rate. The counting process approach has increasingly become the standard framework for analyzing duration data and Andersen et al. (1993) have provided an excellent survey of this literature. Less technical surveys have been given by Klein and Moeschberger (1997), Therneau and Grambsch (2000), and Aalen et al. (2009). The main advantage of this framework is that it allows us to express the duration distribution as a regression model with an error term that is a martingale difference. Regression models with martingale difference errors are the basis for inference in time series models with dependent observations. Hence, it is not surprising that inference is much simplified by using a similar representation in duration models.

To start the discussion, we first introduce some notation. A counting process $\{N(t) ; t \geq 0\}$ is a stochastic process describing the number of events in the interval $[0, t]$ as time proceeds. The process contains only jumps of size +1 . For single duration data, the event can only occur once, because the units are observed until the event occurs. Therefore we introduce the observation indicator $Y(t)=I(T \geq t)$ that equal to 1 if the unit is under observation at time $t$ and zero after the event has occurred. The counting process is governed by its random intensity process $Y(t) \lambda(t)$, with $\lambda(t)$ is the hazard in (4). If we consider a small interval $(t-d t, t]$ of length $d t$, then $Y(t) \lambda(t)$ is the conditional probability that the increment $\mathrm{d} N(t)=N(t)-N(t-d t)$ jumps in that interval given all that has happened until just before $t$. By specifying the intensity as the product of this observation indicator and the hazard rate we effectively limit the number of occurrences of the event to one. It is essential that the observation indicator only depends on events up to time $t$.

Usually, some of the observations are right-censored $\tilde{T}=\min \left(T, C_{r}\right)$. By defining the observation indicator as the product of the indicator $I(t \leq T)$ and, if necessary, an indicator of the observation plan, we capture when a unit is at risk for the event. A related concept is left-truncation. Left truncation occurs when individuals are only observed conditional on survival up till some duration $C_{l}$, the age of military examination in our application. In the case of right censoring and left-truncation the at-risk indicator: $Y(t)=I(t \leq T) I\left(t \leq C_{r}\right) I\left(t \geq C_{l}\right)$. We assume that $C_{r}, C_{l}$ and $T$ are conditionally independent given $X$. The history up to $t, \bar{Y}(t)$ is assumed to be a left continuous function of $t$. The history of the whole process also includes the (history of the) the covariates treatment and mediator. Thus, we have

$$
\operatorname{Pr}(\mathrm{d} N(t)=1 \mid \bar{Y}(t), D, X, Q)=Y(t) \lambda(t \mid X, D, Q)
$$

A fundamental result in the theory of counting processes, the Doob-Meyer decomposition ${ }^{11}$, allows us to write

$$
\mathrm{d} N(t)=Y(t) \lambda(t \mid \bar{X}(t) D, X, Q) \mathrm{d} t+\mathrm{d} M(t)
$$

with $M(t), t \geq 0$ a martingale with conditional mean and variance

$$
\begin{aligned}
\mathrm{E}(\mathrm{d} M(t) \mid \bar{Y}(t), D, X, Q) & =0 \\
\operatorname{Var}(\mathrm{d} M(t) \mid \bar{Y}(t), D, X, Q) & =Y(t) \lambda(t \mid D, X, Q) \mathrm{d} t
\end{aligned}
$$

The (conditional) mean and variance of the counting process are equal, so that the disturbances in (A.3) are heteroscedastic. The probability in (A.2) is 0 , if the unit is no longer under observation.

\footnotetext{
${ }^{11}$ Doob (1953) published the Doob decomposition theorem which gives a unique decomposition for certain discrete time martingales. Meyer (1963) proved a continuous time version of the theorem, which became known as the Doob-Meyer decomposition. Both Andersen et al. (1993) and Aalen et al. (2009) provide a thorough discussion of this theorem.
} 
A counting process can be considered as a sequence of Bernoulli experiments because, if $\mathrm{d} t$ is small, (A.4) and (A.5) give the mean and variance of a Bernoulli random variable. The relation between the counting process and the sequence of Bernoulli experiments is given in (A.3), which can be considered as a regression model with an additive error that is a martingale difference. This equation resembles a time-series regression model. The Doob-Meier decomposition is the key to the derivation of the distribution of the estimators, because the asymptotic behavior of partial sums of martingales is well-known.

Note that the standard Cox model solves $\mathrm{E}[U(\theta)]=0$ with

$$
U(\theta)=\int\left[X^{*}-\frac{\sum Y(t) X^{*} e^{\theta X^{*}}}{\sum Y(t) e^{\theta X^{*}}}\right] \mathrm{d} N(t)
$$

where $X^{*}=(X, D, Q)^{\prime}$ and $\theta=(\beta, \gamma, \alpha)^{\prime}$.

We begin with a proof of the unbiased of the inverse probability weighted Cox estimator give in equation (5). This applies for the case of the pure selection model in which the hazard function does not include a mediator $Q$.

\section{Proof of equation (5): IPW Cox is unbiased:}

First we derive $\mathrm{E}\left[\sum Y(t) W D e^{\gamma D}\right], \mathrm{E}\left[\sum Y(t) W e^{\gamma D}\right], \mathrm{E}[W \mathrm{~d} N(t)]$, and $\mathrm{E}[W D \mathrm{~d} N(t)]$. Redefine the propensity score $p(d)=\operatorname{Pr}\left(D_{i}=d \mid X_{i}\right)$, with $d=0,1$. Note that the integral of the sum is equal to the sum of the integrals.

$$
\begin{aligned}
\mathrm{E}\left[\sum Y(t) W D e^{\gamma D}\right] & =\mathrm{E}\left[S(t \mid D, X) W D e^{\gamma D}\right] \\
& =\int \sum_{d} p(d) \mathrm{E}\left[S(t \mid D=d, X=x) \frac{d e^{\gamma d}}{p(d)}\right] f_{X}(x) \mathrm{d} x \\
& =e^{\gamma} S(t \mid D=1)
\end{aligned}
$$

and

$$
\begin{aligned}
\mathrm{E}\left[\sum Y(t) W e^{\gamma D}\right] & =\mathrm{E}\left[S(t \mid D, X) W e^{\gamma D}\right] \\
& =\int \sum_{d} p(d) \mathrm{E}\left[S(t \mid D=d, X=x) \frac{e^{\gamma d}}{p(d)}\right] f_{X}(x) \mathrm{d} x \\
& =e^{\gamma} S(t \mid D=1)+S(t \mid D=0)
\end{aligned}
$$

and

$$
\begin{aligned}
\mathrm{E}[W \mathrm{~d} N(t)] & =\mathrm{E}[\lambda(t \mid D, X) S(t \mid D, X) W \mathrm{~d} t] \\
& =\int \sum_{d} p(d) \mathrm{E}\left[f(t \mid D=d, X=x) \frac{1}{p(d)}\right] \mathrm{d} t f_{X}(x) \mathrm{d} x \\
& =[f(t \mid D=1)+f(t \mid D=0)] \mathrm{d} t
\end{aligned}
$$

and

$$
\begin{aligned}
\mathrm{E}[W D \mathrm{~d} N(t)] & =\mathrm{E}[\lambda(t \mid D, X) S(t \mid D, X) W D \mathrm{~d} t] \\
& =\int \sum_{d} p(d) \mathrm{E}\left[f(t \mid D=d, X=x) \frac{d}{p(d)}\right] \mathrm{d} t f_{X}(x) \mathrm{d} x \\
& =f(t \mid D=1) \mathrm{d} t
\end{aligned}
$$


This implies:

$$
\begin{aligned}
\mathrm{E}[U(\gamma)] & =\int\left\{\mathrm{E}[W \cdot D \mathrm{~d} N(t)]-\mathrm{E}[W \mathrm{~d} N(t)] \frac{\mathrm{E}\left[\sum Y(t) \cdot W \cdot D e^{\gamma D}\right]}{\mathrm{E}\left[\sum Y(t) W e^{\gamma D}\right]}\right\} \\
& =\int \mathrm{d} t\left\{f(t \mid D=1)-[f(t \mid D=1)+f(t \mid D=0)] \frac{e^{\gamma} S(t \mid D=1)}{e^{\gamma} S(t \mid D=1)+S(t \mid D=0)}\right\} \\
& =\int \mathrm{d} t\{f(t \mid D=1)-[f(t \mid D=1)+f(t \mid D=0)] \times \\
\left.\frac{e^{\gamma} \lambda(t \mid D=0) S(t \mid D=1)}{e^{\gamma} \lambda(t \mid D=0) S(t \mid D=1)+\lambda(t \mid D=0) S(t \mid D=0)}\right\} & f(t \mid D=1) \\
& =\int \mathrm{d} t\left\{f(t \mid D=1)-[f(t \mid D=1)+f(t \mid D=0)] \frac{f(t \mid D=1)+f(t \mid D=0)}{f(t \mid D=0}\right\}=0
\end{aligned}
$$

In moving to the last line we assume $\lambda(t \mid D=1)=e^{\gamma} \lambda(t \mid D=0)$.

\section{Proof of equation (7): IPW Gompertz is unbiased}

In a parametric PH model the log-likelihood in counting process notation is (Andersen and Borgan 1985):

$$
\ln L_{i}=\int\left[\ln \lambda_{0}\left(t_{i} ; \alpha\right)+\gamma D_{i}\right] \mathrm{d} N\left(t_{i}\right)-\int_{0}^{1} Y_{i}(s) \lambda_{0}(s ; \alpha) e^{\gamma D_{i}} d s
$$

where $\lambda_{0}(t ; \alpha)$ is the baseline hazard with parameters $\alpha$, e.g. for a Gompertz baseline hazard $\lambda_{0}(t ; \alpha)=$ $e^{\alpha_{0}+\alpha_{1} t}$. Standard maximum likelihood estimation solves the roots of the derivatives of the loglikelihood:

$$
\begin{aligned}
U_{\alpha}(\theta) & =\sum_{i=1}^{N}\left[\int \frac{\partial \lambda_{0}\left(t_{i} ; \alpha\right) / \partial \alpha}{\lambda_{0}\left(t_{i} ; \alpha\right)} \mathrm{d} N\left(t_{i}\right)-\int_{0}^{1} Y_{i}(s) \frac{\partial \lambda_{0}(s ; \alpha)}{\partial \alpha} e^{\gamma D_{i}} \mathrm{~d} s\right] \\
U_{\gamma}(\theta) & =\sum_{i=1}^{N}\left[\int D_{i} \mathrm{~d} N\left(t_{i}\right)-D_{i} \int_{0}^{1} Y_{i}(s) \lambda_{0}(s ; \alpha) e^{\gamma D_{i}} \mathrm{~d} s\right]
\end{aligned}
$$

with $\theta=(\alpha, \gamma)^{\prime}$ and $U_{\alpha}(\theta)$ and $U_{\gamma}(\theta)$ are the gradients of the log-likelihood w.r.t. $\alpha$ and $\gamma$. The IPW version includes the weights $W$ in equation (A.12) and (A.13). Because our main parameter of interest is $\gamma$ we only focus on $U_{\gamma}(\theta)$. To proof (7) we use similar reasoning as above. First, we derive $\mathrm{E}[W D \mathrm{~d} N(t)]$ and $\mathrm{E}\left[\sum Y(t) \lambda_{0}(t ; \alpha) e^{\gamma D} W D\right]$.

$$
\begin{aligned}
\mathrm{E}\left[\sum Y(t) W \lambda_{0}(t ; \alpha) e^{\gamma D} W D\right] & =\mathrm{E}\left[\lambda_{0}(t ; \alpha) e^{\gamma D} S(t \mid D, X) W D\right] \\
& =\int \sum_{d} p(d) \mathrm{E}\left[\lambda_{0}(t ; \alpha) e^{\gamma D} S(t \mid D=d, X=x) \frac{d e^{\gamma d}}{p(d)}\right] f_{X}(x) \mathrm{d} x \\
& =e^{\gamma} \lambda_{0}(t ; \alpha) S(t \mid D=1)=f(t \mid D=1)
\end{aligned}
$$

From (A.10) we have $\mathrm{E}[W D \mathrm{~d} N(t)]=f(t \mid D=1) \mathrm{d} t$. Thus, if we assume the right parametric model this implies that $U_{\gamma}(\theta)$ has zero mean.

\section{Proof of equation (7): IPW Gamma-Gompertz is unbiased}

In a MPH model with a parametric baseline hazard and a unit-mean Gamma-distributed unobserved heterogeneity with variance $\sigma^{2}$ the (unconditional) hazard is:

$$
\lambda(t \mid D)=\frac{\lambda_{0}(t ; \alpha) e^{\gamma D}}{1+\sigma^{2} \int_{0}^{t} \lambda_{0}(s ; \alpha) e^{\gamma D} d s}
$$


and the likelihood (in counting process notation) is:

$$
L_{i}=\left[\frac{\lambda_{0}(t ; \alpha) e^{\gamma D}}{1+\sigma^{2} \int Y_{i}(s) \lambda_{0}(s ; \alpha) e^{\gamma D} d s}\right]^{\mathrm{d} N_{i}(t)}\left[1+\sigma^{2} \int Y_{i}(s) \lambda_{0}(s ; \alpha) e^{\gamma D} d s\right]^{-1 / \sigma^{2}}
$$

IPW solves the roots of the weighted derivatives of the log-likelihood. The weighted derivative w.r.t. $\gamma$ is:

$$
U_{\gamma}(\theta)=\sum_{i=1}^{N}\left[\int \frac{W_{i} D_{i}}{1+\sigma^{2} \int Y_{i}(s) \lambda_{0}(s ; \alpha) e^{\gamma D} d s} \mathrm{~d} N_{i}(t)-\frac{W_{i} D_{i} \int Y_{i}(t) \lambda_{0}(t ; \alpha) e^{\gamma D} d t}{1+\sigma^{2} \int Y_{i}(s) \lambda_{0}(s ; \alpha) e^{\gamma D} d s}\right]
$$

To prove (7) we use similar reasoning as above. First, we derive

$$
\begin{aligned}
\mathrm{E}\left[\frac{W D}{1+\sigma^{2} \int Y(s) \lambda_{0}(s ; \alpha) e^{\gamma D} d s} \mathrm{~d} N(t)\right] & =\mathrm{E}\left[\frac{W D \lambda_{0}(t ; \alpha) e^{\gamma D} Y(t) d t}{1+\sigma^{2} \int_{0}^{t} \lambda_{0}(s ; \alpha) e^{\gamma D} d s}\right] \\
& =\int \sum_{d} p(d) \mathrm{E}\left[\frac{\lambda_{0}(t ; \alpha) e^{\gamma D} S(t \mid D=d, X=x)}{1+\sigma^{2} \int_{0}^{t} \lambda_{0}(s ; \alpha) e^{\gamma D} d s} \frac{d e^{\gamma d}}{p(d)}\right] \mathrm{d} t f_{X}(x) \mathrm{d} x \\
& =\frac{\lambda_{0}(t ; \alpha) e^{\gamma D}}{1+\sigma^{2} \int_{0}^{t} \lambda_{0}(s ; \alpha) e^{\gamma D} d s} S(t \mid D=1) \mathrm{d} t=f(t \mid D=1) \mathrm{d} t
\end{aligned}
$$

and

$$
\begin{aligned}
\mathrm{E}\left[\sum \frac{W D Y(t) \lambda_{0}(t ; \alpha) e^{\gamma D}}{1+\sigma^{2} \int Y(s) \lambda_{0}(s ; \alpha) e^{\gamma D} d s}\right] & = \\
& =\int \sum_{d} p(d) \mathrm{E}\left[\frac{\lambda_{0}(t ; \alpha) e^{\gamma D} S(t \mid D=d, X=x)}{1+\sigma^{2} \int_{0}^{t} \lambda_{0}(s ; \alpha) e^{\gamma D} d s} \frac{d e^{\gamma d}}{p(d)}\right] f_{X}(x) \mathrm{d} x \\
& =f(t \mid D=1)
\end{aligned}
$$

Thus, if we assume the right parametric model for the baseline hazard and a Gamma distribution for the unobserved heterogeneity (A.17) has mean zero. ${ }^{12}$

We now turn our attention to specifications that include a mediator $Q$ and provide a proof for Theorem 1 on the identification of the decomposition.

\section{Proof Theorem 1 and equation (12) for Cox $\mathbf{P} \mathbf{H}^{13}$ :}

The direct effect $\theta(d)$ solves $\mathrm{E}[U(\theta(d))]=0$ with $U(\theta(d))$

$$
U(\theta(d))=\int W(d)\left[D-\frac{\sum Y(t) W(d) D e^{\gamma D}}{\sum Y(t) W(d) e^{\theta D}}\right] \mathrm{d} N(t)
$$

Again we first derive $\mathrm{E}\left[\sum Y(t) W(d) D e^{\theta D}\right], \mathrm{E}\left[\sum Y(t) W(d) e^{\theta D}\right], \mathrm{E}[W(d) \mathrm{d} N(t)]$, and $\mathrm{E}[W(d) D \mathrm{~d} N(t)]$.

$$
\begin{aligned}
\mathrm{E}\left[\sum Y(t) W(d) D e^{\theta D}\right] & =\mathrm{E}\left[S(t \mid D, Q, X) \cdot W(d) \cdot D e^{\theta(d) D}\right] \\
& =\int e^{\theta(d)} \mathrm{E}\left[S(t \mid D=1, Q=q, X=x) \frac{\operatorname{Pr}(D=d \mid Q, X) f_{Q}(q \mid x)}{\operatorname{Pr}(D=d \mid X)}\right] \mathrm{d} q f_{X}(x) \mathrm{d} x \\
& =\int e^{\theta(d)} \mathrm{E}\left[S(t \mid D=1, Q=q, X=x) f_{Q}(q \mid D=d, X)\right] \mathrm{d} q f_{X}(x) \mathrm{d} x \\
& =e^{\theta(d)} S(t \mid D=1, Q(d))
\end{aligned}
$$

\footnotetext{
${ }^{12}$ The proof for any other MPH model with known functional form of the baseline hazard and given distribution of the unobserved heterogeneity is essentially the same.

${ }^{13}$ The proofs for the Gompertz PH and the Gamma-Gompertz MPH model are very similar and not shown here.
} 
From line two to three we use Bayes' rule.

$$
\begin{aligned}
\mathrm{E}\left[\sum Y(t) W(d) e^{\theta(d) D}\right] & =\mathrm{E}\left[S(t \mid D, Q, X) \cdot W(d) e^{\theta(d) D}\right] \\
& =\int \sum_{k} \mathrm{E}\left[S(t \mid D=k, Q=q, X=x) f_{Q}(q \mid D=d, X)\right] \mathrm{d} q f_{X}(x) \mathrm{d} x \\
& =e^{\theta(d)} S(t \mid D=1, Q(d))+S(t \mid D=0, Q(d))
\end{aligned}
$$

and

$$
\begin{aligned}
\mathrm{E}[W(d) \mathrm{d} N(t)] & =\mathrm{E}[\lambda(t \mid D, Q, X) S(t \mid D, Q, X) \cdot W(d) \mathrm{d} t] \\
& =\int \sum_{k} \mathrm{E}\left[f(t \mid D=k, Q=q, X=x) f_{Q}(q \mid D=d, X)\right] \mathrm{d} t \mathrm{~d} q f_{X}(x) \mathrm{d} x \\
& =[f(t \mid D=1, Q(d))+f(t \mid D=0, Q(d))] \mathrm{d} t
\end{aligned}
$$

and

$$
\begin{aligned}
\mathrm{E}[W(d) D \mathrm{~d} N(t)] & =\mathrm{E}[\lambda(t \mid D, Q, X) S(t \mid D, Q, X) \cdot W(d) \cdot D \mathrm{~d} t] \\
& =\int \mathrm{E}\left[f(t \mid D=1, Q=q, X=x) f_{Q}(q \mid D=d, X)\right] \mathrm{d} t f_{X}(x) \mathrm{d} x \\
& =f(t \mid D=1, Q(d)) \mathrm{d} t
\end{aligned}
$$

This implies:

$$
\begin{aligned}
\mathrm{E}[U(\theta(d))]= & \int\left\{\mathrm{E}[W(d) \cdot D \mathrm{~d} N(t)]-\mathrm{E}[W(d) \mathrm{d} N(t)] \frac{\mathrm{E}\left[\sum Y(t) \cdot W(d) \cdot D e^{\theta(d) D}\right]}{\mathrm{E}\left[\sum Y(t) \cdot W(d) e^{\theta(d) D}\right]}\right\} \\
= & \int \mathrm{d} t\{f(t \mid D=1, Q(d))-[f(t \mid D=1, Q(d))+f(t \mid D=0, Q(d))] \times \\
= & \left.\frac{e^{\theta(d)} S(t \mid D=1, Q(d))}{e^{\theta(d)} S(t \mid D=1, Q(d))+S(t \mid D=0, Q(d))}\right\} \\
= & \int \mathrm{d} t\{f(t \mid D=1, Q(d))-[f(t \mid D=1, Q(d))+f(t \mid D=0, Q(d))] \times \\
& \left.\frac{e^{\theta(d)} \lambda(t \mid D=0, Q(d)) S(t \mid D=1, Q(d))}{e^{\theta(d)} \lambda(t \mid D=0, Q(d)) S(t \mid D=1, Q(d))+\lambda(t \mid D=0, Q(d)) S(t \mid D=0, Q(d))}\right\} \\
& \left.\frac{f(t \mid D=1, Q(d))-[f(t \mid D=1, Q(d))+f(t \mid D=0, Q(d))] \times}{f(t \mid D=1, Q(d))+f(t \mid D=0, Q(d))}\right\}=0
\end{aligned}
$$




\section{Appendix B Additional Tables and Figures}

Table B.1: Ordered Probit estimates of IQ-level, by levels of education

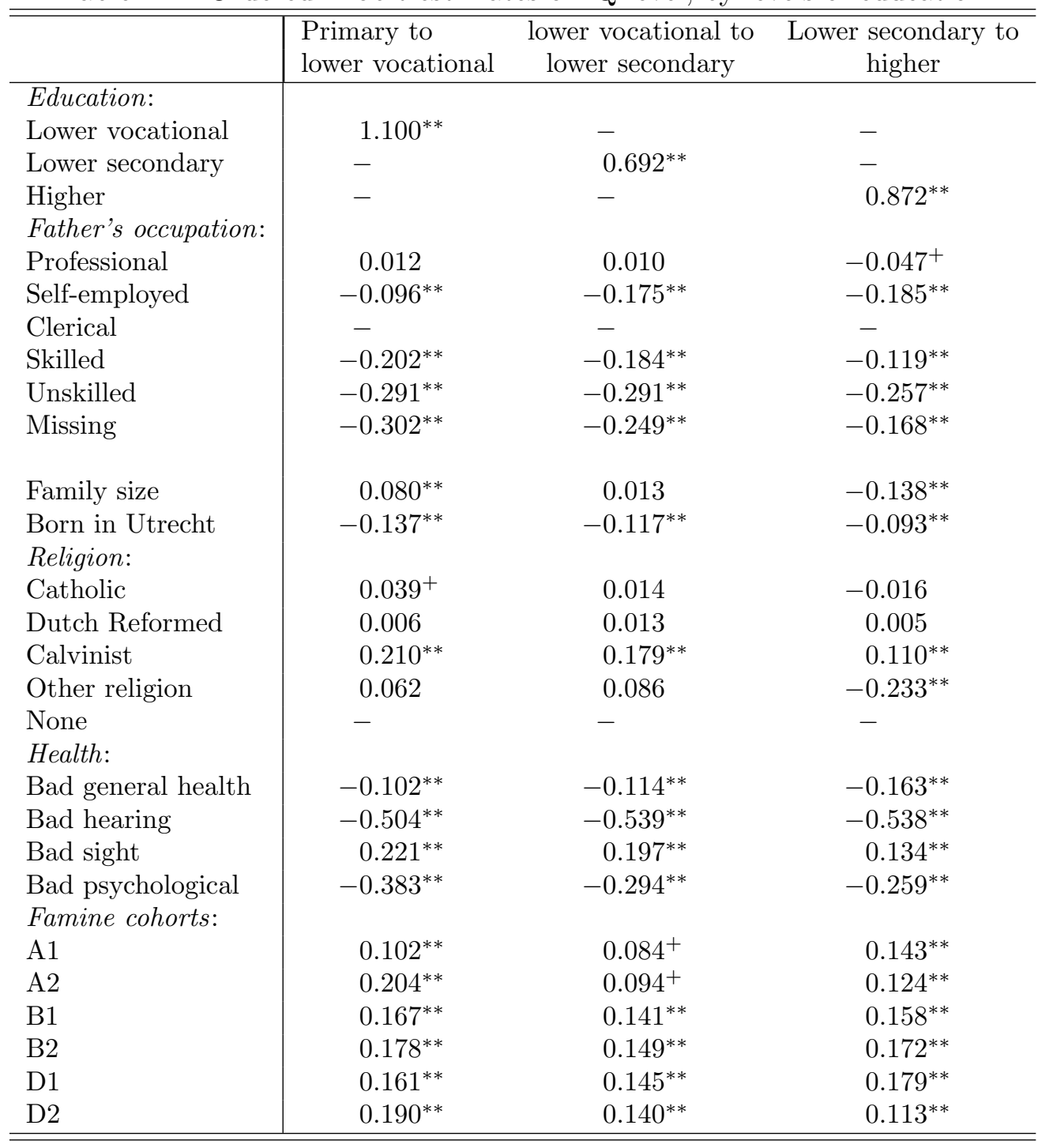

${ }^{+} p<0.05$ and ${ }^{* *} p<0.01$

Famine cohorts from Ravelli et al. (1976): born in 7 cities in the West of Netherlands and A1: born Jan 1944- May 1944; A2: born Jun 1944- Oct 1944; B1: born Nov 1944- Jan 1944; B2: born Feb 1945- May 1945; D1: born Jun 1945- Sep 1945; D2: born Oct 1945Dec 1945. 
Table B.2: Probit estimates of propensity scores ignoring IQ, pairwise comparisons

\begin{tabular}{l|ccc}
\hline \hline & $\begin{array}{c}\text { Primary to } \\
\text { lower vocational }\end{array}$ & $\begin{array}{c}\text { Lower vocational to } \\
\text { lower secondary }\end{array}$ & $\begin{array}{c}\text { Lower secondary to } \\
\text { higher }\end{array}$ \\
\hline Father's occupation: & $-0.221^{* *}$ & $0.123^{* *}$ & $0.478^{* *}$ \\
Professional & $-0.386^{* *}$ & -0.030 & $-0.276^{* *}$ \\
Self-employed & - & - & - \\
Clerical & $-0.404^{* *}$ & $-0.413^{* *}$ & $-0.581^{* *}$ \\
Skilled & $-0.581^{* *}$ & $-0.460^{* *}$ & $-0.616^{* *}$ \\
Unskilled & $-0.443^{* *}$ & $-0.334^{* *}$ & $-0.205^{* *}$ \\
Missing & & & \\
& $0.260^{* *}$ & $0.151^{* *}$ & 0.001 \\
Family size & $-0.252^{* *}$ & 0.057 & $0.082^{+}$ \\
Born in Utrecht & & & \\
Religion: & $-0.089^{* *}$ & -0.037 & 0.043 \\
Catholic & $0.154^{* *}$ & -0.002 & -0.040 \\
Dutch Reformed & $0.403^{* *}$ & $-0.068^{+}$ & 0.048 \\
Calvinist & 0.136 & $0.232^{+}$ & 0.086 \\
Other religion & - & - & - \\
None & & & -0.034 \\
Health: & $-0.066^{+}$ & $0.109^{* *}$ & -0.060 \\
Bad general health & $-0.192^{* *}$ & $-0.213^{* *}$ & $0.267^{* *}$ \\
Bad hearing & $0.139^{* *}$ & $0.374^{* *}$ & $-0.077^{* *}$ \\
Bad sight & $-0.448^{* *}$ & $-0.061^{* *}$ & -0.028 \\
Bad psychological & & & -0.062 \\
Famine cohorts: & $0.199^{* *}$ & 0.052 & 0.020 \\
A1 & $0.117^{+}$ & 0.035 & $-0.058^{+}$ \\
A2 & $0.105^{* *}$ & $0.099^{* *}$ & \\
B1 & $0.071^{+}$ & $0.058^{+}$ & 0.026 \\
B2 & -0.017 & $0.099^{* *}$ & \\
D1 & 0.008 & & \\
D2 & & & \\
\hline \hline
\end{tabular}

${ }^{+} p<0.05$ and ${ }^{* *} p<0.01$

Famine cohorts from Ravelli et al. (1976): born in 7 cities in the West of Netherlands and A1: born Jan 1944- May 1944; A2: born Jun 1944- Oct 1944; B1: born Nov 1944- Jan 1944; B2: born Feb 1945- May 1945; D1: born Jun 1945- Sep 1945; D2: born Oct 1945- Dec 1945. 
Table B.3: Standardized bias before and after matching, pairwise comparisons

\begin{tabular}{l|rr|rr|rr}
\hline \hline & \multicolumn{2}{|c|}{ Primary to } & \multicolumn{2}{c|}{$\begin{array}{l}\text { Lower vocational to } \\
\text { lower secondary }\end{array}$} & \multicolumn{2}{c}{$\begin{array}{r}\text { Lower secondary to } \\
\text { higher }\end{array}$} \\
& Before & After & Before & After & Before & After \\
\hline Father's occupation & & & & & & \\
Professional & 4.9 & -0.6 & 20.2 & -0.2 & 48.8 & -0.3 \\
self-employed & -0.9 & -0.3 & 5.4 & -0.0 & -10.1 & -0.3 \\
Skilled & -9.8 & 0.2 & -22.9 & 0.0 & -38.9 & 0.5 \\
Unskilled & -20.4 & 0.4 & -17.0 & -0.1 & -24.2 & 0.1 \\
Missing & -5.9 & -0.7 & -4.8 & 0.1 & -6.1 & 0.1 \\
& & & & & & \\
Family size & 7.6 & -0.2 & 7.5 & -0.1 & -2.4 & 0.7 \\
Born in Utrecht & -11.9 & 0.0 & 2.4 & -0.1 & 3.8 & -0.4 \\
& & & & & & \\
Catholic Religion & -16.1 & -0.5 & -4.9 & 0.2 & 2.3 & 0.5 \\
Dutch Reformed & 12.6 & 0.8 & 0.7 & -0.1 & -2.5 & 0.0 \\
Calvinist & 17.4 & -1.1 & 3.5 & 0.1 & 2.2 & 0.6 \\
Other religion & -0.3 & -0.1 & 3.1 & -0.2 & 2.4 & -0.9 \\
& & & & & & \\
Bad general health & -9.2 & -0.7 & 6.9 & 0.1 & -1.0 & -0.1 \\
Bad hearing & -8.6 & 0.4 & -5.1 & 0.1 & -2.2 & -0.3 \\
Bad sight & 9.9 & -0.2 & 29.6 & -0.2 & 21.6 & -0.8 \\
Bad psychological & -35.9 & -0.2 & -2.2 & 0.1 & -3.9 & 0.1 \\
Famine cohorts: & & & & & & \\
A1 & 4.6 & 0.0 & 0.0 & 0.0 & -0.8 & -0.2 \\
A2 & 2.7 & -0.3 & -0.3 & -0.1 & -0.8 & -0.4 \\
B1 & 2.8 & -0.4 & 2.7 & 0.0 & 0.5 & -0.5 \\
B2 & 4.1 & 0.0 & 2.4 & -0.2 & -3.6 & 0.6 \\
D1 & -2.8 & -0.3 & 0.4 & 0.0 & -2.9 & -0.3 \\
D2 & 0.6 & -0.2 & 3.7 & 0.1 & 4.8 & -0.1 \\
\hline \# obs & 20,272 & \multicolumn{2}{|c|}{27,687} & & 19,497 \\
\hline \hline
\end{tabular}


Table B.4: Probit estimates of propensity scores, pairwise comparisons including IQ

\begin{tabular}{|c|c|c|c|}
\hline & $\begin{array}{l}\text { Primary to } \\
\text { lower vocational }\end{array}$ & $\begin{array}{l}\text { Lower vocational to } \\
\text { lower secondary }\end{array}$ & $\begin{array}{c}\text { Lower secondary to } \\
\text { higher }\end{array}$ \\
\hline \multicolumn{4}{|l|}{ Father's occupation: } \\
\hline Professional & $-0.196^{* *}$ & $0.110^{* *}$ & $0.485^{* *}$ \\
\hline Self-employed & $-0.333^{* *}$ & 0.051 & $-0.175^{* *}$ \\
\hline Clerical & - & - & - \\
\hline Skilled & $-0.263^{* *}$ & $-0.319^{* *}$ & $-0.511^{* *}$ \\
\hline Unskilled & $-0.371^{* *}$ & $-0.310^{* *}$ & $-0.481^{* *}$ \\
\hline Missing & $-0.250^{* *}$ & $-0.231^{* *}$ & $-0.141^{* *}$ \\
\hline Family size & $0.207^{* *}$ & $0.149^{* *}$ & $0.074^{+}$ \\
\hline $\begin{array}{l}\text { Born in Utrecht } \\
\text { Religion: }\end{array}$ & $-0.135^{* *}$ & $0.125^{* *}$ & $0.139^{* *}$ \\
\hline Catholic & $-0.135^{* *}$ & $-0.047^{+}$ & $0.066^{+}$ \\
\hline Dutch Reformed & $0.143^{* *}$ & -0.011 & -0.041 \\
\hline Calvinist & $0.278^{* *}$ & -0.009 & 0.008 \\
\hline Other religion & 0.053 & $0.232^{+}$ & $0.259^{+}$ \\
\hline None & - & - & - \\
\hline \multicolumn{4}{|l|}{ Health: } \\
\hline Bad general health & $-0.060^{+}$ & $0.111^{* *}$ & -0.021 \\
\hline Bad hearing & -0.041 & $-0.147^{* *}$ & -0.008 \\
\hline Bad sight & -0.042 & $0.244^{* *}$ & $0.169^{* *}$ \\
\hline Bad psychological & $-0.154^{* *}$ & $0.068^{* *}$ & 0.047 \\
\hline \multicolumn{4}{|l|}{ Famine cohorts: } \\
\hline A1 & 0.119 & 0.041 & -0.049 \\
\hline $\mathrm{A} 2$ & -0.003 & 0.019 & -0.089 \\
\hline B1 & $0.010^{* *}$ & $0.064^{+}$ & 0.010 \\
\hline $\mathrm{B} 2$ & $-0.030^{+}$ & 0.012 & $-0.107^{* *}$ \\
\hline D1 & $-0.114^{* *}$ & -0.020 & $-0.146^{* *}$ \\
\hline D2 & $-0.127^{+}$ & 0.047 & 0.024 \\
\hline \multicolumn{4}{|l|}{ Comprehensive IQ } \\
\hline 1 (highest) & $1.317^{* *}$ & $0.826^{* *}$ & $1.502^{* *}$ \\
\hline 2 & $0.602^{* *}$ & $0.527^{* *}$ & $0.763^{* *}$ \\
\hline 3 & - & - & - \\
\hline 4 & $-0.590^{* *}$ & $-0.450^{* *}$ & $-0.420^{* *}$ \\
\hline 5 & $-1.254^{* *}$ & $-0.835^{* *}$ & $-0.429^{+}$ \\
\hline 6 (lowest) & $-1.985^{* *}$ & $-1.017^{* *}$ & 0.112 \\
\hline missing & $-0.759^{* *}$ & $0.302^{* *}$ & $0.970^{* *}$ \\
\hline
\end{tabular}

${ }^{+} p<0.05$ and ${ }^{* *} p<0.01$ 
Table B.5: Standardized bias before and after matching, pairwise comparisons (propensity score with IQ)

\begin{tabular}{|c|c|c|c|c|c|c|}
\hline & \multicolumn{2}{|c|}{$\begin{array}{l}\text { Primary to } \\
\text { lower vocational }\end{array}$} & \multicolumn{2}{|c|}{$\begin{array}{l}\text { Lower vocational to } \\
\text { lower secondary }\end{array}$} & \multicolumn{2}{|c|}{$\begin{array}{c}\text { Lower secondary to } \\
\text { higher }\end{array}$} \\
\hline & Before & After & Before & After & Before & After \\
\hline Father's occupation & & & & & & \\
\hline Professional & 4.9 & 1.1 & 20.2 & -0.6 & 48.8 & -0.7 \\
\hline self-employed & -0.9 & 0.7 & 5.4 & 0.3 & -10.1 & -0.8 \\
\hline Skilled & -9.8 & 0.5 & -22.9 & 0.1 & -38.9 & 2.9 \\
\hline Unskilled & -20.4 & 2.1 & -17.0 & 0.1 & -24.2 & -1.0 \\
\hline Missing & -5.9 & 0.9 & -4.8 & -0.6 & -6.1 & 1.1 \\
\hline Family size & 7.6 & -1.0 & 7.5 & -0.4 & -2.4 & 1.3 \\
\hline $\begin{array}{l}\text { Born in Utrecht } \\
\text { Religion }\end{array}$ & -11.9 & 0.4 & 2.4 & -0.2 & 3.8 & -1.2 \\
\hline Catholic & -16.1 & -1.5 & -4.9 & -0.0 & 2.3 & 0.5 \\
\hline Dutch Reformed & 12.6 & 1.8 & 0.7 & 0.1 & -2.5 & -2.6 \\
\hline Calvinist & 17.4 & -2.7 & 3.5 & -0.4 & 2.2 & -0.3 \\
\hline $\begin{array}{l}\text { Other religion } \\
\qquad \text { Health }\end{array}$ & -0.3 & 2.7 & 3.1 & -0.3 & 2.4 & 1.2 \\
\hline Bad general health & -9.2 & 1.7 & 6.9 & 0.1 & -1.0 & -0.1 \\
\hline Bad hearing & -8.6 & 0.4 & -5.1 & -0.3 & -2.2 & -0.8 \\
\hline Bad sight & 9.9 & 0.9 & 29.6 & -0.8 & 21.6 & -1.7 \\
\hline $\begin{array}{l}\text { Bad psychological } \\
\text { Comprehensive IQ }\end{array}$ & -35.9 & 1.8 & -2.2 & -0.3 & -3.9 & 1.1 \\
\hline 1 (highest) & -35.0 & -4.8 & 40.8 & -1.2 & 77.1 & -0.6 \\
\hline 2 & 69.3 & -1.8 & 43.0 & 0.8 & -20.9 & -0.8 \\
\hline 3 & 41.0 & 1.5 & -21.7 & 0.5 & -20.9 & 0.2 \\
\hline 4 & -12.9 & 1.1 & -44.4 & -0.2 & -34.5 & 1.1 \\
\hline 5 & -70.8 & 1.0 & -37.9 & -0.7 & -16.6 & 4.1 \\
\hline 6 (lowest) & -45.5 & 0.3 & -10.6 & 0.7 & -3.5 & -0.7 \\
\hline missing & -9.2 & 0.4 & 4.5 & 0.1 & 3.8 & -0.3 \\
\hline
\end{tabular}


Table B.6: Estimated coefficients included variables in Gamma-Gompertz robust (unadjusted) estimation

\begin{tabular}{l|ccc}
\hline \hline & $\begin{array}{c}\text { Primary to } \\
\text { lower vocational }\end{array}$ & $\begin{array}{c}\text { Lower vocational to } \\
\text { lower secondary }\end{array}$ & $\begin{array}{c}\text { Lower secondary to } \\
\text { higher }\end{array}$ \\
\hline Father's occupation: & -0.026 & 0.001 & 0.030 \\
Professional & $0.160^{+}$ & $0.124^{+}$ & 0.136 \\
Self-employed & - & - & - \\
Clerical & -0.016 & 0.025 & $0.159^{* *}$ \\
Skilled & 0.030 & 0.043 & $0.165^{+}$ \\
Unskilled & $0.201^{* *}$ & $0.184^{* *}$ & 0.123 \\
Missing & & & \\
Family size & $0.180^{+}$ & $0.107^{+}$ & 0.100 \\
Born in Utrecht & $0.281^{* *}$ & $0.194^{* *}$ & 0.102 \\
Religion: & $-0.095^{+}$ & $-0.096^{+}$ & -0.029 \\
Catholic & -0.071 & -0.041 & -0.034 \\
Dutch Reformed & -0.077 & -0.116 & $-0.217^{* *}$ \\
Calvinist & -0.285 & -0.222 & -0.399 \\
Other religion & - & - & - \\
None & & & $0.254^{* *}$ \\
Health: & 0.094 & $0.173^{* *}$ & 0.114 \\
Bad general health & $0.342^{* *}$ & $0.195^{+}$ & -0.023 \\
Bad hearing & -0.041 & -0.047 & $0.109^{+}$ \\
Bad sight & $0.170^{* *}$ & $0.134^{* *}$ & $0.088^{* *}$ \\
Bad psychological & $-10.011^{* *}$ & $-10.091^{* *}$ & $0.932^{* *}$ \\
\hline Scale (constant) & $0.091^{* *}$ & $0.088^{* *}$ & \\
Shape (age) & $0.754^{* *}$ & $0.235^{* *}$ & \\
Gamma-var & & & \\
\hline \hline
\end{tabular}

${ }^{+} p<0.05$ and ${ }^{* *} p<0.01$ 
Table B.7: Sensitivity analysis propensity score with IQ as selection variable: outcome and selection effects (additional covariates)

\begin{tabular}{|c|c|c|c|c|c|c|}
\hline & \multicolumn{2}{|c|}{$\begin{array}{l}\text { Primary to } \\
\text { lower vocational }\end{array}$} & \multicolumn{2}{|c|}{$\begin{array}{c}\text { Lower vocational to } \\
\text { lower secondary }\end{array}$} & \multicolumn{2}{|c|}{$\begin{array}{c}\text { Lower secondary to } \\
\text { higher }\end{array}$} \\
\hline & $\omega$ & $\xi$ & $\omega$ & $\xi$ & $\omega$ & $\xi$ \\
\hline neutral & 0 & 0 & 0 & 0 & 0 & 0 \\
\hline Professional & $\begin{array}{l}-0.188 \\
(0.163)\end{array}$ & $\begin{array}{c}0.168 \\
(0.095)\end{array}$ & $\begin{array}{c}-0.005 \\
(0.097)\end{array}$ & $\begin{array}{l}0.601^{* *} \\
(0.059)\end{array}$ & $\begin{array}{r}-0.075 \\
(0.088)\end{array}$ & $\begin{array}{l}1.105^{* *} \\
(0.061)\end{array}$ \\
\hline Self-employed & $\begin{array}{c}0.180 \\
(0.160)\end{array}$ & $\begin{array}{c}-0.037 \\
(0.113)\end{array}$ & $\begin{array}{l}0.118 \\
(0.114)\end{array}$ & $\begin{array}{c}0.220^{+} \\
(0.078)\end{array}$ & $\begin{array}{c}0.051 \\
(0.120)\end{array}$ & $\begin{array}{c}-0.426^{* *} \\
(0.111)\end{array}$ \\
\hline Skilled & $\begin{array}{c}0.023 \\
(0.087)\end{array}$ & $\begin{array}{c}-0.200^{* *} \\
(0.058)\end{array}$ & $\begin{array}{r}-0.085 \\
(0.059)\end{array}$ & $\begin{array}{c}-0.506^{* *} \\
(0.043)\end{array}$ & $\begin{array}{c}0.111 \\
(0.075)\end{array}$ & $\begin{array}{c}-1.105^{* *} \\
(0.080)\end{array}$ \\
\hline Unskilled & $\begin{array}{c}0.071 \\
(0.105)\end{array}$ & $\begin{array}{c}-0.520^{* *} \\
(0.068)\end{array}$ & $\begin{array}{c}-0.023 \\
(0.084)\end{array}$ & $\begin{array}{c}-0.525^{* *} \\
(0.061)\end{array}$ & $\begin{array}{c}0.082 \\
(0.101)\end{array}$ & $\begin{array}{c}-1.056^{* *} \\
(0.127)\end{array}$ \\
\hline Missing & $\begin{array}{l}0.050 \\
(0.155)\end{array}$ & $\begin{array}{c}-0.227^{+} \\
(0.104)\end{array}$ & $\begin{array}{c}0.282^{+} \\
(0.107)\end{array}$ & $\begin{array}{c}-0.200^{+} \\
(0.087)\end{array}$ & $\begin{array}{c}0.031 \\
(0.144)\end{array}$ & $\begin{array}{r}-0.308^{+} \\
(0.138)\end{array}$ \\
\hline Born in Utrecht & $\begin{array}{c}0.247 \\
(0.131)\end{array}$ & $\begin{array}{c}-0.411^{* *} \\
(0.092)\end{array}$ & $\begin{array}{c}0.236^{+} \\
(0.102)\end{array}$ & $\begin{array}{c}0.094 \\
(0.074)\end{array}$ & $\begin{array}{c}0.091 \\
(0.114)\end{array}$ & $\begin{array}{c}0.132 \\
(0.094)\end{array}$ \\
\hline Catholic & $\begin{array}{c}0.044 \\
(0.089)\end{array}$ & $\begin{array}{c}-0.334^{* *} \\
(0.058)\end{array}$ & $\begin{array}{r}-0.105 \\
(0.061)\end{array}$ & $\begin{array}{r}-0.104^{+} \\
(0.042)\end{array}$ & $\begin{array}{c}0.017 \\
(0.069)\end{array}$ & $\begin{array}{c}0.047 \\
(0.055)\end{array}$ \\
\hline Dutch Reformed & $\begin{array}{r}-0.052 \\
(0.102)\end{array}$ & $\begin{array}{c}0.284^{* *} \\
(0.060)\end{array}$ & $\begin{array}{c}0.037 \\
(0.060)\end{array}$ & $\begin{array}{c}0.020 \\
(0.042)\end{array}$ & $\begin{array}{c}0.337 \\
(0.070)\end{array}$ & $\begin{array}{r}-0.057 \\
(0.055)\end{array}$ \\
\hline Calvinist & $\begin{array}{c}-0.304 \\
(0.274)\end{array}$ & $\begin{array}{c}0.791^{* *} \\
(0.133)\end{array}$ & $\begin{array}{c}0.018 \\
(0.109)\end{array}$ & $\begin{array}{c}0.131 \\
(0.073)\end{array}$ & $\begin{array}{r}-0.207 \\
(0.122)\end{array}$ & $\begin{array}{c}0.069 \\
(0.093)\end{array}$ \\
\hline Other religion & $\begin{array}{c}-0.270 \\
(0.653)\end{array}$ & $\begin{array}{c}-0.005 \\
(0.377)\end{array}$ & $\begin{array}{l}-0.086 \\
(0.444)\end{array}$ & $\begin{array}{c}0.359 \\
(0.248)\end{array}$ & $\begin{array}{c}-0.184 \\
(0.408)\end{array}$ & $\begin{array}{c}0.229 \\
(0.284)\end{array}$ \\
\hline Bad general health & $\begin{array}{c}0.082 \\
(0.111)\end{array}$ & $\begin{array}{c}-0.236^{* *} \\
(0.071)\end{array}$ & $\begin{array}{c}0.131 \\
(0.073)\end{array}$ & $\begin{array}{l}0.188^{* *} \\
(0.051)\end{array}$ & $\begin{array}{l}0.234^{* *} \\
(0.079)\end{array}$ & $\begin{array}{c}-0.022 \\
(0.066)\end{array}$ \\
\hline Bad hearing & $\begin{array}{c}0.363 \\
(0.182)\end{array}$ & $\begin{array}{c}-0.455^{* *} \\
(0.146)\end{array}$ & $\begin{array}{c}0.278 \\
(0.158)\end{array}$ & $\begin{array}{c}-0.307^{+} \\
(0.126)\end{array}$ & $\begin{array}{c}0.143 \\
(0.224)\end{array}$ & $\begin{array}{c}-0.191 \\
(0.196)\end{array}$ \\
\hline Bad sight & $\begin{array}{c}-0.008 \\
(0.109)\end{array}$ & $\begin{array}{c}0.235^{* *} \\
(0.066)\end{array}$ & $\begin{array}{c}-0.030 \\
(0.066)\end{array}$ & $\begin{array}{c}0.639^{* *} \\
(0.044)\end{array}$ & $\begin{array}{c}-0.032 \\
(0.065)\end{array}$ & $\begin{array}{c}0.436^{* *} \\
(0.051)\end{array}$ \\
\hline Bad psychological & $\begin{array}{r}0.215^{+} \\
(0.088)\end{array}$ & $\begin{array}{c}-0.771^{* *} \\
(0.063)\end{array}$ & $\begin{array}{c}0.137^{+} \\
(0.067)\end{array}$ & $\begin{array}{c}-0.048 \\
(0.048)\end{array}$ & $\begin{array}{c}0.184^{+} \\
(0.077)\end{array}$ & $\begin{array}{c}-0.099 \\
(0.064)\end{array}$ \\
\hline
\end{tabular}

Based on adding $U$ to propensity score with probabilities of $U$ from observed probabilities of covariates. No effect would give $\omega=0$ and $\xi=0 .{ }^{+} p<0.05$ and ${ }^{* *} p<0.01$ 


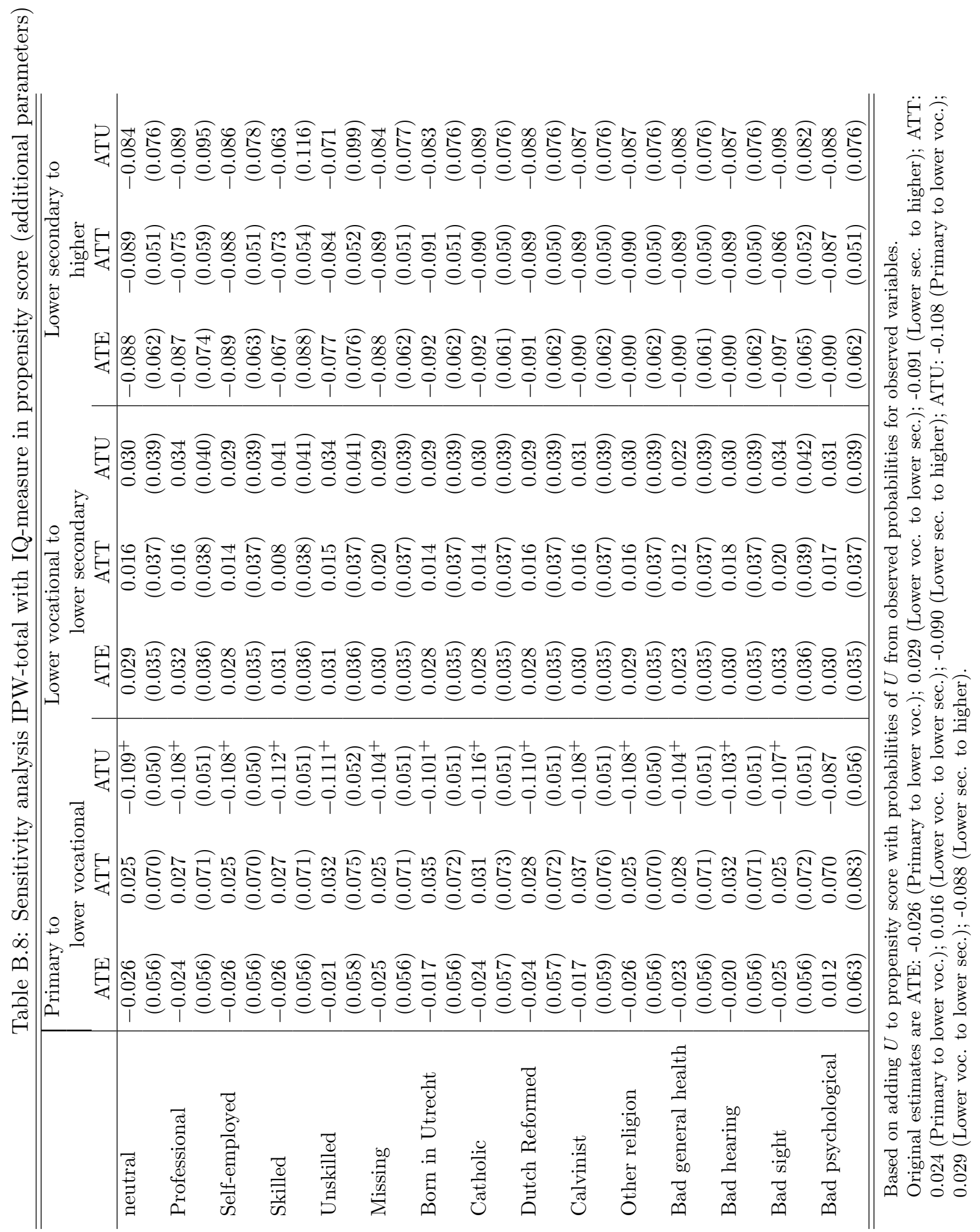


Table B.9: Robust decomposition of effect of education on the mortality rate

\begin{tabular}{|c|c|c|c|c|c|c|}
\hline & \multicolumn{4}{|c|}{ Average treatment effect (ATE) } & \multirow{2}{*}{\multicolumn{2}{|c|}{$\begin{array}{ll}\text { ATT } & \text { ATU } \\
\text { other pathways }\end{array}$}} \\
\hline & \multicolumn{2}{|c|}{ other pathways } & \multicolumn{2}{|c|}{ cognitive ability } & & \\
\hline & $\theta(1)$ & $\theta(0)$ & $\eta(0)$ & $\eta(1)$ & $\theta(1)$ & $\theta(0)$ \\
\hline Cox & & & & & & \\
\hline Primary to & -0.021 & -0.072 & $-0.165^{+}$ & -0.115 & 0.020 & $-0.122^{+}$ \\
\hline lower vocational & $(0.067)$ & $(0.048)$ & $(0.077)$ & $(0.062)$ & $(0.069)$ & $(0.051)$ \\
\hline Lower vocational to & 0.039 & 0.035 & -0.092 & -0.088 & 0.022 & 0.034 \\
\hline lower secondary & $(0.035)$ & $(0.038)$ & $(0.047)$ & $(0.050)$ & $(0.037)$ & $(0.040)$ \\
\hline Lower secondary to & $-0.127^{+}$ & -0.076 & -0.064 & -0.114 & -0.090 & -0.086 \\
\hline higher & $(0.050)$ & $(0.069)$ & $(0.068)$ & $(0.083)$ & $(0.051)$ & $(0.076)$ \\
\hline Gamma-Gompertz & & & & & & \\
\hline Primary to & -0.019 & -0.071 & $-0.179^{+}$ & $-0.127^{+}$ & 0.023 & $-0.121^{+}$ \\
\hline lower vocational & $(0.071)$ & $(0.048)$ & $(0.083)$ & $(0.065)$ & $(0.072)$ & $(0.051)$ \\
\hline Lower vocational to & 0.042 & 0.043 & -0.095 & -0.096 & 0.025 & 0.042 \\
\hline lower secondary & $(0.038)$ & $(0.044)$ & $(0.050)$ & $(0.051)$ & $(0.039)$ & $(0.047)$ \\
\hline Lower secondary to & $-0.151^{+}$ & -0.094 & -0.070 & -0.128 & -0.105 & -0.109 \\
\hline higher & $(0.061)$ & $(0.081)$ & $(0.081)$ & $(0.098)$ & $(0.062)$ & $(0.090)$ \\
\hline
\end{tabular}

${ }^{+} p<0.05$ and ${ }^{* *} p<0.01$ 


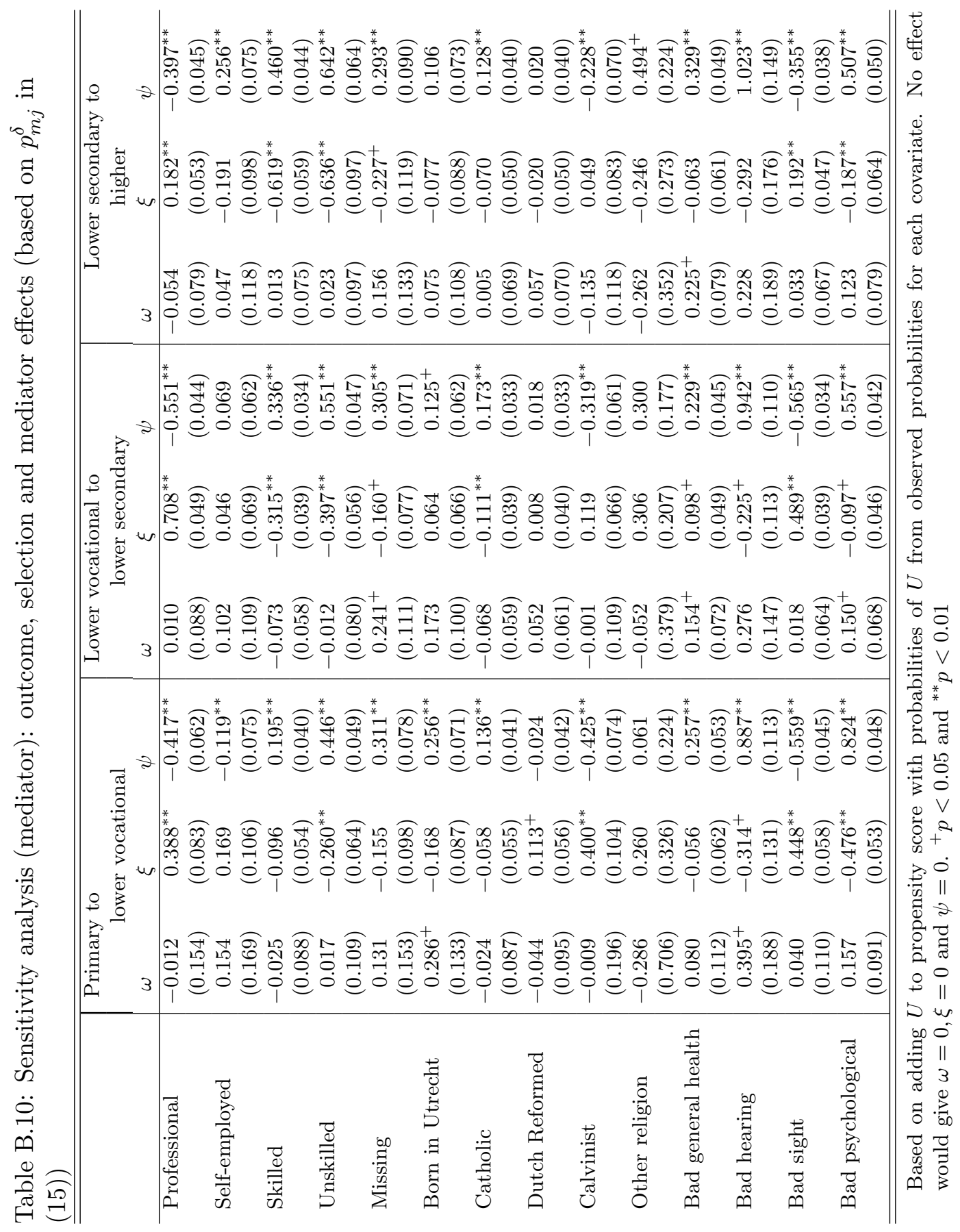


Table B.11: Sensitivity analysis (mediator): effect running through other pathways IPW (ATE), based on $p_{m j}^{\delta}$ in (15).

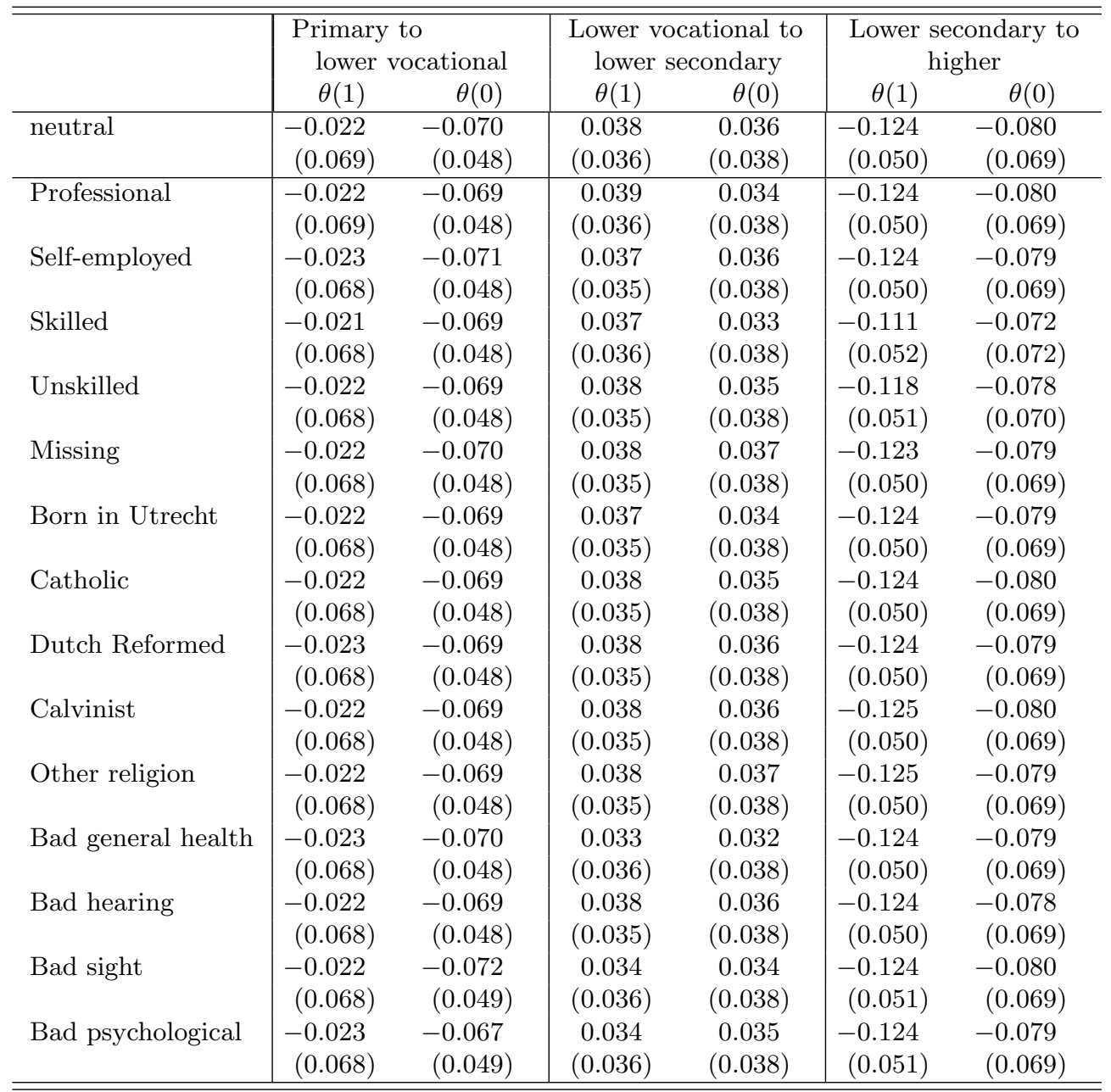

Based on adding $U$ to propensity score with probabilities of $U$ from observed probabilities for observed variables.

Original estimates are $\theta(1):-0.022$ (Primary to lower voc.); 0.038 (Lower voc. to lower sec.); -0.124 (Lower sec. to higher); $\theta(0)$ : -0.070 (Primary to lower voc.); 0.036 (Lower voc. to lower sec.); -0.079 (Lower sec. to higher). 


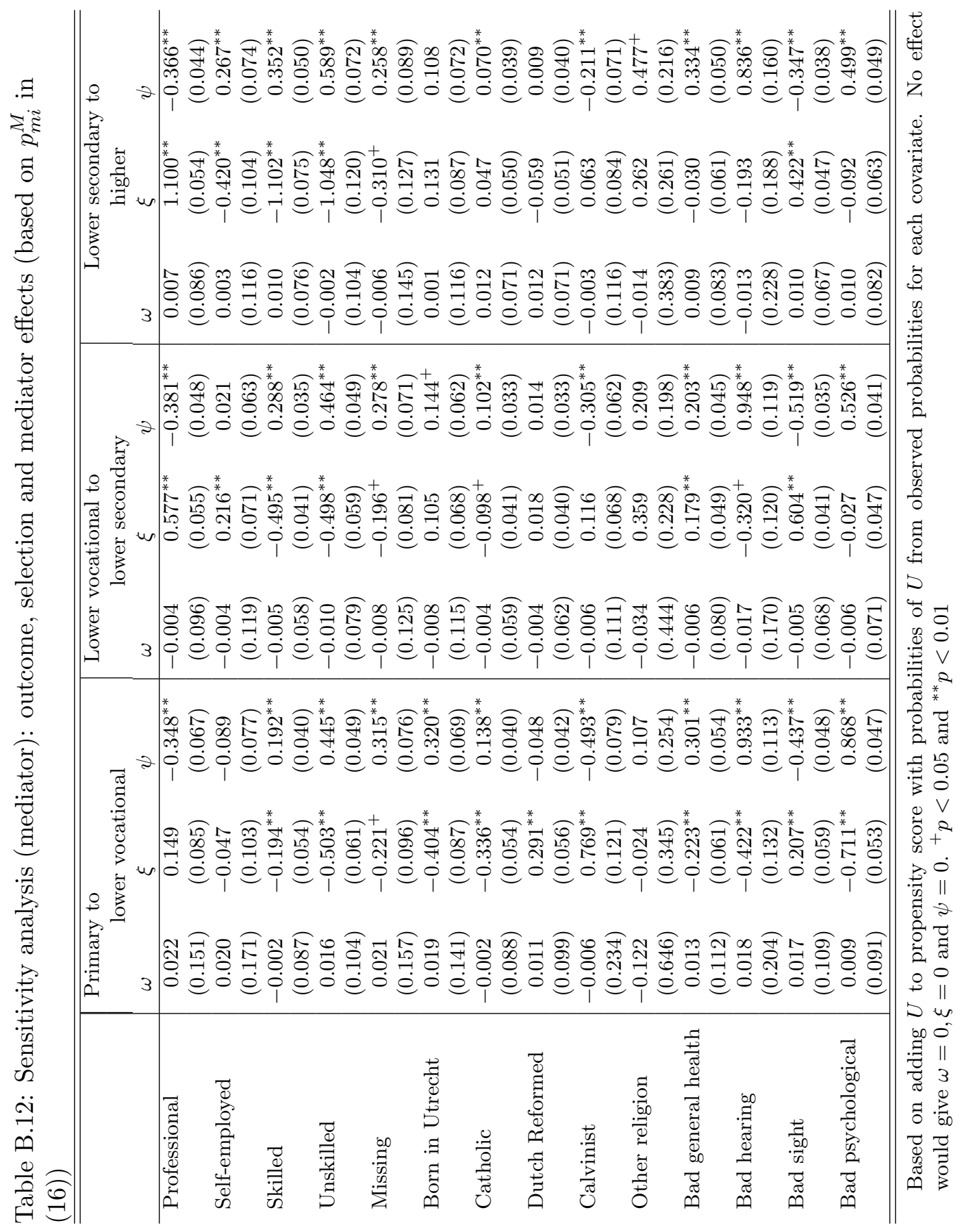


Table B.13: Sensitivity analysis (mediator): effect running through other pathways IPW (ATE), based on $p_{m i}^{M}$ in (16).

\begin{tabular}{|c|c|c|c|c|c|c|}
\hline & \multicolumn{2}{|c|}{$\begin{array}{l}\text { Primary to } \\
\text { lower vocational }\end{array}$} & \multicolumn{2}{|c|}{$\begin{array}{c}\text { Lower vocational to } \\
\text { lower secondary }\end{array}$} & \multicolumn{2}{|c|}{$\begin{array}{c}\text { Lower secondary to } \\
\text { higher }\end{array}$} \\
\hline & $\theta(1)$ & $\theta(0)$ & $\theta(1)$ & $\theta(0)$ & $\theta(1)$ & $\theta(0)$ \\
\hline neutral & $\begin{array}{r}-0.022 \\
(0.069) \\
\end{array}$ & $\begin{array}{r}-0.070 \\
(0.048) \\
\end{array}$ & $\begin{array}{c}0.038 \\
(0.036) \\
\end{array}$ & $\begin{array}{c}0.036 \\
(0.038) \\
\end{array}$ & $\begin{array}{r}-0.124 \\
(0.050) \\
\end{array}$ & $\begin{array}{c}-0.080 \\
(0.069) \\
\end{array}$ \\
\hline Professional & $\begin{array}{r}-0.022 \\
(0.068)\end{array}$ & $\begin{array}{r}-0.070 \\
(0.048)\end{array}$ & $\begin{array}{c}0.037 \\
(0.036)\end{array}$ & $\begin{array}{c}0.036 \\
(0.038)\end{array}$ & $\begin{array}{r}-0.126 \\
(0.055)\end{array}$ & $\begin{array}{c}-0.083 \\
(0.079)\end{array}$ \\
\hline Self-employed & $\begin{array}{r}-0.022 \\
(0.069)\end{array}$ & $\begin{array}{r}-0.070 \\
(0.048)\end{array}$ & $\begin{array}{c}0.038 \\
(0.036)\end{array}$ & $\begin{array}{c}0.036 \\
(0.038)\end{array}$ & $\begin{array}{r}-0.125 \\
(0.051)\end{array}$ & $\begin{array}{r}-0.080 \\
(0.069)\end{array}$ \\
\hline Skilled & $\begin{array}{r}-0.022 \\
(0.068)\end{array}$ & $\begin{array}{r}-0.070 \\
(0.048)\end{array}$ & $\begin{array}{c}0.038 \\
(0.036)\end{array}$ & $\begin{array}{c}0.037 \\
(0.038)\end{array}$ & $\begin{array}{r}-0.124 \\
(0.056)\end{array}$ & $\begin{array}{r}-0.080 \\
(0.089)\end{array}$ \\
\hline Unskilled & $\begin{array}{r}-0.020 \\
(0.068)\end{array}$ & $\begin{array}{r}-0.068 \\
(0.049)\end{array}$ & $\begin{array}{c}0.037 \\
(0.036)\end{array}$ & $\begin{array}{c}0.035 \\
(0.038)\end{array}$ & $\begin{array}{r}-0.123 \\
(0.053)\end{array}$ & $\begin{array}{r}-0.079 \\
(0.075)\end{array}$ \\
\hline Missing & $\begin{array}{c}-0.022 \\
(0.068)\end{array}$ & $\begin{array}{c}-0.069 \\
(0.048)\end{array}$ & $\begin{array}{c}0.038 \\
(0.035)\end{array}$ & $\begin{array}{c}0.036 \\
(0.038)\end{array}$ & $\begin{array}{r}-0.124 \\
(0.050)\end{array}$ & $\begin{array}{r}-0.080 \\
(0.069)\end{array}$ \\
\hline Born in Utrecht & $\begin{array}{r}-0.022 \\
(0.068)\end{array}$ & $\begin{array}{c}-0.069 \\
(0.048)\end{array}$ & $\begin{array}{c}0.038 \\
(0.035)\end{array}$ & $\begin{array}{c}0.036 \\
(0.038)\end{array}$ & $\begin{array}{r}-0.124 \\
(0.050)\end{array}$ & $\begin{array}{r}-0.080 \\
(0.069)\end{array}$ \\
\hline Catholic & $\begin{array}{r}-0.023 \\
(0.068)\end{array}$ & $\begin{array}{r}-0.070 \\
(0.049)\end{array}$ & $\begin{array}{c}0.038 \\
(0.035)\end{array}$ & $\begin{array}{c}0.036 \\
(0.038)\end{array}$ & $\begin{array}{r}-0.125 \\
(0.050)\end{array}$ & $\begin{array}{r}-0.080 \\
(0.069)\end{array}$ \\
\hline Dutch Reformed & $\begin{array}{r}-0.023 \\
(0.069)\end{array}$ & $\begin{array}{r}-0.070 \\
(0.049)\end{array}$ & $\begin{array}{c}0.035 \\
(0.035)\end{array}$ & $\begin{array}{c}0.036 \\
(0.038)\end{array}$ & $\begin{array}{c}-0.124 \\
(0.050)\end{array}$ & $\begin{array}{c}-0.079 \\
(0.069)\end{array}$ \\
\hline Calvinist & $\begin{array}{c}-0.022 \\
(0.068)\end{array}$ & $\begin{array}{c}-0.070 \\
(0.049)\end{array}$ & $\begin{array}{c}0.038 \\
(0.035)\end{array}$ & $\begin{array}{c}0.036 \\
(0.038)\end{array}$ & $\begin{array}{r}-0.124 \\
(0.050)\end{array}$ & $\begin{array}{c}-0.079 \\
(0.069)\end{array}$ \\
\hline Other religion & $\begin{array}{r}-0.022 \\
(0.068)\end{array}$ & $\begin{array}{r}-0.070 \\
(0.045)\end{array}$ & $\begin{array}{c}0.038 \\
(0.035)\end{array}$ & $\begin{array}{c}0.036 \\
(0.038)\end{array}$ & $\begin{array}{r}-0.124 \\
(0.050)\end{array}$ & $\begin{array}{r}-0.079 \\
(0.069)\end{array}$ \\
\hline Bad general health & $\begin{array}{c}-0.022 \\
(0.068)\end{array}$ & $\begin{array}{c}-0.068 \\
(0.048)\end{array}$ & $\begin{array}{c}0.038 \\
(0.036)\end{array}$ & $\begin{array}{c}0.036 \\
(0.038)\end{array}$ & $\begin{array}{r}-0.124 \\
(0.050)\end{array}$ & $\begin{array}{r}-0.080 \\
(0.069)\end{array}$ \\
\hline Bad hearing & $\begin{array}{c}-0.022 \\
(0.068)\end{array}$ & $\begin{array}{c}-0.069 \\
(0.048)\end{array}$ & $\begin{array}{c}0.038 \\
(0.035)\end{array}$ & $\begin{array}{c}0.036 \\
(0.038)\end{array}$ & $\begin{array}{r}-0.124 \\
(0.050)\end{array}$ & $\begin{array}{c}-0.079 \\
(0.069)\end{array}$ \\
\hline Bad sight & $\begin{array}{r}-0.020 \\
(0.069)\end{array}$ & $\begin{array}{c}-0.071 \\
(0.048)\end{array}$ & $\begin{array}{c}0.036 \\
(0.036)\end{array}$ & $\begin{array}{c}0.036 \\
(0.038)\end{array}$ & $\begin{array}{r}-0.124 \\
(0.051)\end{array}$ & $\begin{array}{r}-0.080 \\
(0.069)\end{array}$ \\
\hline Bad psychological & $\begin{array}{c}-0.022 \\
(0.068)\end{array}$ & $\begin{array}{c}-0.065 \\
(0.048)\end{array}$ & $\begin{array}{c}0.038 \\
(0.036)\end{array}$ & $\begin{array}{c}0.035 \\
(0.038)\end{array}$ & $\begin{array}{c}-0.124 \\
(0.050)\end{array}$ & $\begin{array}{r}-0.080 \\
(0.069)\end{array}$ \\
\hline
\end{tabular}

Based on adding $U$ to propensity score with probabilities of $U$ from observed probabilities for observed variables.

Original estimates are $\theta(1)$ : -0.022 (Primary to lower voc.); 0.038 (Lower voc. to lower sec.); -0.124 (Lower sec. to higher); $\theta(0)$ : -0.070 (Primary to lower voc.); 0.036 (Lower voc. to lower sec.); -0.079 (Lower sec. to higher). 